NBER WORKING PAPER SERIES

\title{
DYNAMIC MODELING OF THE PRODUCT \\ LIFE CYCLE IN THE COMMERCIAL \\ MAINFRAME COMPUTER MARKET, \\ 1968-1982
}

\author{
Shane M. Greenstein \\ James B. Wade
}

Working Paper 6124

\section{NATIONAL BUREAU OF ECONOMIC RESEARCH 1050 Massachusetts Avenue \\ Cambridge, MA 02138 \\ August 1997}

We would like to thank Tim Bresnahan, Glenn Carroll, Paul Klemperer, Steve Klepper, and Pablo Spiller for useful conversations. Suggestions from Rob Porter and two anonymous referees significantly improved the paper. Greenstein thanks the Center for Economic Policy Research at Stanford University, the University of Illinois Research Board and NSF IRI92-09321 for financial support. He also thanks the Computer Industry Project at Stanford University for their hospitality when this paper was completed. Sandra Ospina provided excellent research assistance. This paper is part of NBER's research program in Productivity. Any opinions expressed are those of the authors and not those of the National Bureau of Economic Research.

(C) 1997 by Shane M. Greenstein and James B. Wade. All rights reserved. Short sections of text, not to exceed two paragraphs, may be quoted without explicit permission provided that full credit, including $(\mathcal{C}$ notice, is given to the source. 
Dynamic Modeling of the Product Life Cycle in the

Commercial Mainframe Computer Market, 1968-1982

Shane M. Greenstein and James B. Wade

NBER Working Paper No. 6124

August 1997

Productivity

\section{ABSTRACT}

This research investigates product life cycles in the commercial mainframe computer market.

We show that empirical studies conducted at the product level are useful for investigating processes underlying product life cycles. We use hazard models with time-varying covariates to estimate the probability of product exit and Poisson models to estimate the probability of introduction. We measure the importance of different aspects of market structure, such as the degree of competitiveness, cannibalization, vintage, product niche and firm effects. We find some evidence of a relationship between the determinants of product exit and product entry.

Shane M. Greenstein

Kellogg Graduate School of Management

Northwestern University

Evanston, IL 60208-2013

and NBER

s-greenstein1@nwu.edu
James B. Wade

Department of Business Administration

University of Illinois

1206 South 6th Street

Champaign, IL 61820

jbwade@montana.cba.uiuc.edu 


\section{Introduction}

Innovation is rampant in adolescent industries. Old products die or evolve and new products replace them. Each new generation of products offers new features, extends the range of existing features, or lowers their cost. Vendors quickly imitate each other's products, turning a novelty into a standard feature. Innovative leadership may change rapidly among firms or competing products-lines. These events are often given the label "the product life cycle."

This article empirically investigates the product life cycle of commercial mainframe computer systems during an especially dynamic period, from the late 1960 s to the early 1980 s. Focusing on the life-cycle of products seems natural in light of the industry's dynamic history. In this time period the leading firms hardly changed at all, while the leading products turned over hundreds of times. New computer systems embodying best-practice technology advanced at a rapid rate. ${ }^{1}$ Each new product embodied new capabilities at lower prices. The frequent turnover in products diffused new technology across the economy into computer-using businesses. ${ }^{2}$

What economic mechanisms determined the rate at which products turned over in this industry? Our approach is both eclectic and empirical. We measure how market structure and other economic factors shape product introduction and turnover in the context of the commercial mainframe industry. We emphasize two related themes. First, many theories predict that market structure should influence the introduction of new products as well as their post-entry survival. We test a wide variety of specifications for the influence of market structure on introduction and

1 Hedonic studies have shown that each new generation of products embodied dramatic declines in the price of basic functionality. See, for example, Dulberger [1989], Gordon [1989], and Triplett [1989].

2 See Greenstein [1994] for evidence that the technical sophistication of the average system in use advanced at a rate not far from best practice. 
exit. Second, many models predict that the same economic factors influence entry and exit in the same direction. We search for evidence that allows us to either accept, reject, or refine the prediction that the determinants of entry and exit are closely related.

We estimate the rate at which a firm introduces a new system into a market and we also estimate the instantaneous probability of an existing system exiting the market. Unlike most previous empirical research on the product life-cycle, the identities of leading products (instead of firms) are the key events for understanding structural change and diffusion of technology. ${ }^{3}$ While using many of the same methods, we depart from studies done by organizational ecologists who, thus far, have focussed on predicting entry and exit processes at the organizational level. ${ }^{4}$ Like a few recent papers on the computer industry dynamics, we make the unit of analysis the product. ${ }^{5}$ This approach is natural for the mainframe market because firms did not turnover rapidly, but products did. In addition, this approach takes advantage of historical differences in market structure between product niches. We are, thus, able to identify the role of market structure in influencing product turnover while controlling for cross-sectional and time-dependent differences in niches.

3 For previous work on the product cycle see Gort and Klepper [1982], Klepper and Graddy [1990]. See Klepper [1996] for a review and theoretical synthesis of the life-cycle literature. See Bresnahan and Greenstein [1995] for an analysis of the long run changes in the structure of computer industry over the last thirty-five years, where the emphasis is on changes in the dominant firm.

4 See Carroll [1984], Hannan and Freeman [1989], Singh and Lumsdon [1990] for a review of this literature.

5 Research using the product as the unit of observation includes Stavins [1996], who examines entry and exit within the PC industry using information obtained from hedonic estimation. Khanna [1994] examines heterogeneity in firm strategies for stretching technical frontiers within the large scale computer industry. Hartman and Teece [1990] examine introduction strategies and hedonic pricing in the minicomputer industry. Oliner [1992] examines retirement patterns and values among IBM mainframes. 
Our measurement goals necessitate use of time-varying covariates in our analysis of exit and entry. We estimate hazard rates (Tuma [1980]) and Poisson models (Cameron and Trivedi [1986]). These are well-known statistical methods in organizational ecology (e.g., Hannan and Freeman [1989]) and elsewhere in applied econometrics, but they are relatively unused in the literature on the diffusion of new technology (For an exception, see Saloner and Shepard [1996]). We show that the use of time-varying covariates is not difficult to estimate or interpret in these models, and offers a potentially useful and simple method for research of technology diffusion at the product level. For example, we consider how the size of a system, its market niche, and its technical vintage will affect product introductions and turnover. We also analyze more complex economic effects, such as the likely impact of product cannibalization and the introduction of close and distant substitutes by competitors.

Our results document several interesting findings. First, we find that several features of market structure predict product introductions and exit; no simple explanation will be satisfactory. Second, we find that later vintage products do not have shorter lives. Entry also weakly increases over time. Third, we find strong evidence of important differences between firms in their product life cycle behavior with respect to both entry and exit. Fourth, we find evidence of differences between niches in product life cycles, particularly with respect to exit and less so with respect to entry. Fifth, cannibalization within a market niche strong predicts a product's death, but cannibalization in "neighboring" niches has no effect. We offer several interpretations of this finding in the paper. Sixth, competition from products within a niche and surrounding niches have a significant impact on a product's exit, but only competition within a niche affects new entry. Finally, we do not find a strong relationship between the determinants 
of entry and exit behavior. Some of the economic factors shaping product life post-entry have a similar influence on product entry and some do not. We offer several interpretations for these findings within the text.

\section{The Commercial Mainframe Industry and the Product Life Cycle}

This section describes our research strategy for measuring the product life-cycle in the mainframe computing market from 1968 to 1983 . Our strategy is both eclectic and practical. We first review what is known about the product cycle in the computing. We then propose a measurement framework. We then discuss empirical hypotheses that lend themselves to measurement, motivating them with well-known theoretical arguments. Throughout the discussion, we focus on the entry of new products and the exit of existing products, leaving analysis of pricing, market share and its growth to further work. ${ }^{6}$

\section{a. What is known about the product life-cycle in computing}

By the late 1960s a small number of firms marketed products in the large scale commercial computing industry and only a few highly publicized entry and exit episodes marked changes in the identify of the firms (Fisher, Mancke and McKie [1983]). In the late 1960s and 1970s there was relatively frequent turnover of products, accompanied by unabated technical improvement. Among the contemporary trade press, the phrase "product life cycle" became

6 See, for example, Bresnahan and Greenstein [1995, 1997], Greenstein [1994], Greenstein [1996].

7 During the period of our study only seven new firms entered the market (only two on a large scale) and four exited (two of those through merger). See our data below. 
short-hand for regular and repeated patterns of outcomes associated with turnover of products. ${ }^{8}$

Figure 1 shows that many products entered and exited the market over the time period of our study (We explain the sources for this data below). Typically, each firm carried one or several product lines, where each line consisted of many fully compatible or partially compatible computer systems. Many firms also marketed systems that were backward compatible with previous generations of systems. All this took place within a market structure that many contemporaries characterized as dominant/fringe. While the industry's revenues grew steadily over time and sales varied across all firms from one year to the next, IBM consistently garnished the largest share of sales overall by a long margin, particularly for general purpose mainframes.

What lies behind these new products? New inventions spurred firms to try adding new features to both new and old designs. Many new products contained larger computing memory and faster CPU speeds at lower cost. ${ }^{9}$ Internal and external storage capacity also expanded, and input/output speeds increased. New and better programming languages diffused across many systems. By the end of the 1970s a third-party software industry had grown, further diffusing refined application software across many computing platforms. Other peripherals such as printers, terminals, and many other minor components also improved. Solid-state circuitry,

8 Different parts of the computer trade press and computer consulting industry used the phrase, "product lifecycle," for very different purposes. See Inmon [1985], Phister [1979], Friedman and Cornford [1989], Fisher, McGowan, and Greenwood[1983] or Fisher, McKie and Mancke [1983] for different treatments. When economists have turned to measuring events associated with product turnover, it is usually in the context of measuring the rate of technical change and improvement in economic welfare. See Dulberger [1989], Gordon [1989], Trajtenberg [1990], and Triplett [1989].

9 See Gordon [1989], Dulberger [1989], Cole et al [1986], Triplett [1986, 1989] and Oliner [1992]. 
improved air-conditioning units, and more compact design also made systems more reliable and lowered servicing costs.

These new features permitted users to address increasingly complex problems and perform tasks that could not be previously attempted. ${ }^{10}$ Hardware architecture and operating system software underwent many refinements. Large databases became easier to use, broadening their potential applicability. This was the era of the development of timesharing applications and applications that allowed users to perform quick queries of centralized databases. ${ }^{11}$ This helped computing expand into ever more essential enterprise functions. From the buyer's perspective, the "product life cycle" in this time period involved either installing new systems or upgrading, retrofitting, and improving existing systems. As buyers learned about new needs and discovered new technological opportunities, buyers reevaluated their situations. Buyers then modified the memory and speed of their CPU, but kept other durable investments in software or peripherals. Or buyers enhanced particular software programs or peripheral components, but not other components. This type of upgrading behavior could feed on itself. Peripheral and software upgrading could induce bottlenecks in CPUs, which induced further CPU upgrading, which, in turn, induced further peripheral and software enhancements. Thus, upgrading to larger CPU capacity was essential to taking advantage of technical improvements embedded in new systems. Reduction in the price of computing capacity enabled

10 There was rarely a clear association between change in price per computing unit and the introduction of particular products (or other market events). Scientific and engineering users were the first to take advantage of faster computing speeds and larger memories. These functions eventually diffused across many users. See Fischer et al [1983], Friedman and Cornford [1989], Bresnahan and Greenstein [1995].

11 Service bureaus, insurance and banking users, and many large organizations employed these developments in new inventory and reservation systems. 
many users to take advantage of technical change in complementary components.

From the vendor's perspective, the "product life cycle" concerned product design, sales and marketing issues. All parts of this cycle -- designing, prototyping, manufacturing, initial rolling out, selling systems, servicing, and customer-upgrading -- involved technical and commercial risks. Vendors could expect a fraction of their customers to desire frequent upgrades of systems or backward compatible improved designs. Vendors could also expect a fraction of old customers and new customers (who were starting green-field computing centers) to compare the technical capabilities of all new systems. Therefore, vendors could expect their old product designs to become technically obsolete with the passage of time, the entry of more competitors, the expansion of technical possibilities, and the expansion of buyers' needs. If a new design met with any initial commercial success, then later parts of the "cycle" involved potential up-grades and sales of complementary components.

Patterns associated with the product life cycle, whether viewed by the seller or buyer, were thought to vary across market segments and across time. Throughout this time period, scientific computing was served by vendors who raced to be first with the largest and fastest new system. ${ }^{12}$ It is an open question whether this resulted in observably different product cycles for larger systems. In addition, few substitutes for general-purpose mainframes were available in 1965, but over the 1970s several firms developed general-purpose minicomputer hardware and software for small decentralized tasks. It is an open question whether this resulted in observably different product cycles for smaller systems. By 1981 vendors of superminis also began to offer

\footnotetext{
${ }^{12}$ See, for example, Fisher et al [1983] or Khanna [1994] for analysis of competition at the high-end.
} 
users larger applications and viable growth paths for their systems. Some buyers could (and some did) break up their computing needs into smaller units. ${ }^{13}$

\section{b. Definitions.}

Since our study focuses on the introduction and exit of a product, we need a practical definition of a "product." We also need a practical definition for "introduction/entry" and "exit." These are the basic building blocks of our empirical framework.

Our definition of a product will focus on the bundles of attributes embedded within a product. When we say "product," we mean a typical arrangement of computer components commonly associated with different capabilities and prices. Different products refers to arrangements with significantly different attributes, which usually implies different costs, prices, and sometimes customer bases. A user typically buys a product, configures it with standard and customized peripherals, and overlays onto it standard and customized software applications.

These definitions are easier to implement in practice than one might first conjecture. For all practical purposes, market surveyors decide whether different products, as labeled by vendors, correspond with different designs or bundles of attributes. To some degree, surveyors rely on vendors, who choose whether or not to differentiate between products, but surveyors also rely on their own judgement about similarities between products in use. We say more about practical product definitions below, but we note that our definition of a product is similar to what hedonic research has used (with a few exceptions noted below).

To guard against falsely measuring the entry of phantom systems (or "vaporware"), we

13 Note that personal computers were only beginning to diffuse by 1981 and were largely employed as sophisticated terminals. PCS were not viewed as substitutes for mainframes until much later. 
do not include models which, while listed in the data source, ultimately have no sales. After the last sale, which we measure with hindsight, we say that a product has exited. While the length of time that a product sells is determined by a complex interaction of both supply and demand forces, we adopt this definition for practical measurement purposes. It also corresponds with long-established practice within the computer industry to distinguish between a product still for sale and not.

\section{c. The determinants of the product cycle}

We are interested in measuring the determinants of entry and exit of products. We found some guidance for empirically modeling this situation from the applied theoretical literature on firm entry and exit in uncertain environments. ${ }^{14}$ Though theoretical models tend to very specific about market structure and competitive behavior and the source of uncertainty, we take inspiration from several commonalities across models. First, market structure may influence entry and exit behavior in predictable directions. Second, there may be a systematic relationship between empirical patterns of entry and exit. We offer a brief synthesis.

Models of firm entry and exit tend to assume the firm has a single product. The discrete decision to enter and exit a market occurs simultaneously for a product and its firm. Prospective firms/products either choose to enter with a new product or wait another period and reconsider again. Similarly, existing firms/products who have already entered either choose to stay another period or exit the market. These decisions are modeled as rational calculations in uncertain

14 See, e.g., Pakes and McGuire [1994], Klepper [1996], Jovanovich and McDonald [1994a, 1994b], Rosenberg [1982]. Within the synthesis in Klepper [1996], these years seem to fit the situation where "leadership of the industry stabilizes" (p. 564) after an initial shake out, but does not seem to fit the characterization that "recent entrants account for a disproportionate share of product innovations" (p. 565). Also, we do not think this is a market where "innovations fall off over time" (p. 565) after a peak in the growth in the number of producers. 
environments. Each decision takes place when the anticipated benefits exceed the anticipated costs.

The net benefits from entry depend on anticipated post-entry events. For example, the net benefits from entering a new market increase when total demand increases for all computers (e.g., when the size of the market grows) or when more buyers value the new functionality embodied in a frontier product. Similarly, entry increases if the costs of entry decline. These costs decline when exogenous technical change lowers those costs, when the costs of components from upstream suppliers decline, or when firms lower the costs of distribution.

The net benefits for entry also increase when less competition is anticipated from rivals, either due to less competitive pricing behavior or fewer substitutes from rivals (e.g., due to a rival's inefficiencies, etc.). In most models, the anticipated intensity of rivalry increases with the number of firms, holding constant for demand and cost conditions ${ }^{15}$. "Spillovers" between firms can increase or decrease product entry, depending on how spillovers are appropriated. For example, one firms' experience with the reducing costs may also lead to information that helps other firms decrease their costs. In another example, one firm may also learn about key features of demand from another's experience.

By extension decisions to exit (or stay) depend on the realization of post-entry events. If the costs associated with on-going production and distribution activities are higher than anticipated, then existing firms/products are more likely to exit. If entry costs are sunk (after being expended), increasing those sunk entry costs will influence the anticipated net

\footnotetext{
${ }^{15}$ For instance, researchers have found evidence that high numbers of firms present in a given year generally leads to a higher firm failure rates (Hannan and Freeman, 1989).
} 
benefits/costs of entry, but not necessarily change the net benefits from exit unless these sunk costs effect the general equilibrium of the market. For example, sunk investments influence dynamic calculations of others firms, which changes the value of competing products. By similar reasoning, the net benefits associated with exit increase as demand declines, or it may go up or down when products receive more spillovers from other products. Firms also may learn about the intensity of demand, the appeal of their product's design, or the appropriate design-modification in a learning-by-using environment.

The anticipated uncertainty surrounding exit/stay decisions feeds back into entry decisions. In highly uncertain markets, the net benefits of entry may increase or decrease when uncertainty increases, depending on specific theoretical assumptions about risk neutrality, the distribution of uncertainty, its skewness and payoff structure. If there is little post-entry uncertainty, then the same factors which influence exit/stay decisions will influence the anticipated benefits of entry decisions. In contrast, if post-entry learning is highly idiosyncratic to each product, there may be little relationship between the economic factors that influence the entry of a product and the exit of them. In many models in which post-entry learning plays a large role, each new product serves as an experiment with highly variable prospects. When entry costs are sufficiently low, for example, the majority of products quickly fail, with only a few succeeding for any length of time.

At this stage in our empirical research with a newly assembled set of data, we are hesitant to presume very much about the specific features of firm behavior and market equilibrium, particularly for purposes of estimating product turnover as a function of structural parameters of learning, costs, demand and substitution. We stay close to the issues found in the 
literature, but we attempt to estimate a more modest model using reduced form statistical methods.

We emphasize two themes. First, market structure should influence entry and exit in predictable ways. The same economic factors may be common to all products and result in similar economic trade-offs for all products, resulting in similar entry/exit behavior. For example, costs of introducing new products may be lower for one firm and not others; then the rate of entry for that firm should be higher compared to others. If costs have declined for everyone due to exogenous technical change, then there should be differences over time in the rate of product entry and exit for all firms. Demand conditions may also change for all firms, particularly when those demand changes are linked to fluctuations in macro-economic demand. Niche computing applications may also be subject to niche-specific demand and supply conditions, leading to similar patterns of product entry and exit within a niche, but very different patterns across niches.

Second, it is possible for entry and exit decisions to be closely related. In models with little post-entry uncertainty there is a relationship between market structure, entry behavior and exit behavior. When little post-entry uncertainty influences forecasts about post-entry profitability, then market structure influences the anticipated value of entering a new market and also influences the realized value associated with exiting.

In sum, the literature directs us to investigate features of market structure that predict entry and exit behavior. We will focus on descriptive statistical issues and then offer an interpretation. Our statistical model focuses on the following questions:

Q1. Does entry or exit differ across years? Products become associated with the year a 
firm introduces them, corresponding with exogenous declines in costs or year-specific changes in demand conditions. Much of the trade-press presumes that life-cycles have shortened in later years.

Q2. Does the age of a product have any relationship to entry and exit? Old products exit as they fall technically behind; leaving only better products to survive. ${ }^{16}$ Established products may acquire a good reputation, support services and software. New entry may become more likely in market niches where existing products are more distant from the technical frontier. Thus, the age of existing systems may have a non-liner relationship to entry and exit decisions.

Q3. Does entry or exit differ across firms? Firms differ in their cost structure, distribution networks, efficiencies, and other firm-specific product-line strategies.

Q4. Does market niche predict entry or exit? Different niches have been associated with different customer bases, different applications and possibly different upgrade and replacement cycles. ${ }^{17}$

Q5. How does the number of competitors influence entry and exit? All other things equal, the degree of competitiveness within a market niche may influence the anticipated and realized benefits from entry and exit. Competition from direct substitutes will be more constraining than competition from distant substitutes.

Q6. Does cannibalization influence product turnover? Cannibalization behavior may correspond with the obsolescence of an old product, particularly in markets where firms can

\footnotetext{
16 This was an important phenomena in Berndt and Griliches [1993] and Stavins [1996].

17 For example, many high-end computers are sold to scientific users who favor new computing architectures, inducing "racing" by high-end designers to stretch technical frontier. See Khanna's [1994] analysis of large scale computing. Racing behavior might induce shorter product cycles and more frequent product introductions.
} 
anticipate the post-entry life-cycle of a product. As an empirical matter, however, it may be difficult to measure obsolescence separately from unmeasured factors correlated with timing. ${ }^{18}$

Q7. Do the same factors predict entry and exit? We will explore whether any factors influence both the decision to enter and exit in the same direction.

\section{Estimation of the Model}

We adopt a flexible estimation framework which measures the influence of time-invariant and time-varying determinants of product life. The former include factors such as market segment, system size, vendor, and vintage. The latter include factors such as degree of competition from close and distant substitutes, cannibalization from close and distant substitutes and age of a product. First we describe our methodology for measuring exit. Next we discuss the measurement of entry.

\section{a. Model Exit}

In our analyses of model exits, we use the individual model as the unit of analysis. A model is said to fail in that year if there is no longer an increase in the installed base. Writing a likelihood function for this process involves specifying the joint probability of the observations. In this analysis, each case provides two types of information, the state occupied (alive or dead) and the time spent in the state. Following Tuma [1980], the likelihood function for any observation $I$ can be written as:

$$
\mathrm{L}_{\mathrm{i}}=\mathrm{Gi}(\mathrm{t})[\mu \mathrm{i}(\mathrm{t})]^{\phi}
$$

18 Product obsolescence in a technical sense is exogenous, but the timing of cannibalization is endogenous market event. Unmeasured error (in product obsolescence) might correlate with the decision to introduce a new product in a niche in which the firm has an existing product. 
Where Gi(t) is the survivor function, $\mu \mathrm{i}(\mathrm{t})$ is the hazard rate, and $\phi$ is a variable that is one for uncensored cases and zero otherwise. We begin by assuming a constant rate $\mu(t)=\gamma$. The survivor function for this model is $G(t)=\exp [-\gamma t]$. The following specification is used:

$$
\mu(t)=\exp \left[\beta \mathbf{X}^{\prime}(t)\right]
$$

where $\mu(t)$ is the instantaneous failure rate for a system at time $t$ and $\mathbf{X}^{\prime}$ is a vector of independent variables. Each of the parameters $\exp \left[\beta_{n} X_{n}\right]$ can be thought of as multipliers of the rate and can be estimated by using maximum likelihood as outlined above. For more details on this approach, see Tuma [1980] and Carroll [1983].

In order to control for the age of the product, we can construct a series of age dummies and insert these dummies into the constant rate model. Another approach, which we did consider, is to fit the hazard rate to a specific functional form for changing hazard rates over time. For instance, the Gompertz function assumes that the hazard rate is an exponential function of duration (in this case product age). One advantage of using a continuous time model such as the Gompertz is that only one degree of freedom is sacrificed. An advantage of using a constant rate model with age dummies is that one can control for nonlinearities in age that do not perfectly fit a specific function. Because the range of age is our sample is relatively small (only 24 models out of 175 lived over 6 years and the maximum age was 9.6 years old), the loss of degrees of freedom is relatively low from using dummies. Thus, we prefer a more flexible modeling framework and estimated a constant rate model.

One problem in our data is that it only extends back to 1968 . Thus, a system that was alive before 1968 would have no observations and be left censored. The likelihood function specified above is not exactly correct if the entire event history of a case is not included. 
Unfortunately, the correct likelihood that would take account of left censored observations is very difficult to estimate. In order to minimize this problem we only include models in our analysis for which the entire event history is known (i.e. those founded in 1968 or later).

In order to analyze model failure, each model's life history was broken up into yearly spells with all but the last cell being censored on the right. Time varying covariates are updated at the beginning of the year for each system. We estimate a model-specific failure rate assuming that the failure rate is influenced by a set of independent variables.

\section{b. Model Introductions}

To estimate the rate at which firms introduce new products in a given market niche, we utilize Poisson regression. More specifically, we assume that the number of product introductions by firm in a given size class at time $t\left(\mathrm{Y}_{\mathrm{t}}\right)$ follows a Poisson process and is conditional on a set of covariates $\mathbf{X}$. This implies that

$$
\operatorname{Pr}\left(Y_{t}=y_{t} \mid X^{\prime}\right)=\left(e^{-\lambda\left(X^{\prime}\right)} \lambda\left(X^{\prime}\right)^{y t}\right) / y_{t} !
$$

The parameter $\lambda_{t}$, which is the mean of the number of product introductions by a firm in a size class in year $\mathrm{t}$, is assumed to take the form:

$$
\left.\lambda(t)=\exp \left[\beta \mathbf{X}^{\prime}(t)\right]\right]
$$

where $\mathbf{X}^{\prime}$ is a vector of independent variables. Each of the parameters $\exp \left[\beta_{\mathrm{n}} X_{\mathrm{n}}\right]$ can be thought of as multipliers of the rate. The parameters are estimated by minimizing the following log likelihood function:

$\mathscr{L}=\sum_{t}\left[-\lambda_{t}+y_{t} \beta^{\prime} x_{t}-\ln y_{t} !\right]$

Use of Poisson regression has one serious limitation. A Poisson model assumes that the 
mean of the expected event counts equals its variance. Often, however, count data is over dispersed, i.e., the variance of the expected event exceeds the mean. Using the Poisson model in this instance can lead to erroneously small standard errors (Cameron and Trevidi [1990]). Because the negative binomial and the Poisson are nested models, it is possible to test for over dispersion. We will also test our data using the Kolmogorov-Smirnov test. As we will show below, both tests cannot reject that hypothesis that our data are distributed Poisson.

Finally, we adopt one convention. If a firm has never previously had products in a size class, no observation is recorded for that firm in that year in that size class. We do this for two reasons. First, the decision to participate in a size class is distinct from the decision to introduce new products in a size class that the firm has already entered. Second, it is quite rare to observe any firm enter a new size class; thus, we can only identify behavior associated with introducing products to familiar market niches.

\section{c. Trading off Complete Data with other Limitations}

There is one important limitation to the statistical approach we take in this study and these limitations are best illustrated in comparison to the existing hedonic estimates for this era's computer market. Previous hedonic research on the computing industry has helped economists compile somewhat incomplete data on the era's product prices and product characteristics. ${ }^{19}$ Incomplete data sets are not as useful for models of product turnover, unfortunately. The features of products typically found in hedonic studies of computers -- prices, speed and memory -- are

19 Since features of the most popular models reflect the dramatic technical trends changing the overall computer market, incomplete data sets are adequate for purposes of estimating changes in hedonic surfaces over time (See Triplett [1989] for a survey). 
only available for the most popular products in this market (i.e., those with larger market share). ${ }^{20}$ Yet, the most popular products live longest. To focus solely on popular products imparts a selection bias into any study of product birth and turnover, missing products with smaller sales.

We prefer to try to develop results based only on information we can gather for all products. As we describe below, we are able to compile a complete censuses of products, their market niches, their age, their firm sponsor and degrees of competition in market niche. We cannot, on the basis of data now available to us, tell whether the addition of more information about a select set of popular models alters our conclusions. We hope to make progress on this issue in future work. ${ }^{21}$

\section{Data}

This paper's data on computer prices, quantities, and vintages comes from industry censuses from International Data Corporation's (IDC) EDP Industry Reports (EDP/IR) ${ }^{22}$. We rely on IDC's definition of a system, always utilizing the first definition they use if there is any ambiguity. IDC estimated the number of installations of each type of computer system and, until 1981, estimated the monthly rental at which an average type of system leased ${ }^{23}$. The data in this

20 Market surveyors tend to concentrate their attention on only the most popular products.

21 E.g., Greenstein [1996] attempts to predict installed base and prices with incomplete characteristics data.

22 Patrick McGovern began compiling this census in 1962 in Computers and Automation magazine. It continued in modified form under IDC auspices from the mid 1960s onward. The archives of the Charles Babbage Institute at the University of Minnesota contains a collection. This paper also makes use of a set of EDP Industry Reports contained at the Library for the Graduate School of Business at Stanford University.

${ }^{23}$ Phister identifies several years in which IDC revised the reported number of installations in previous years, particular for IBM models in 1967-1972. In those cases, we use Phister's reported updates. This makes this paper's 
paper begins with the December 31, 1968 report and ends with the January 1, 1983 report. The first year in which IDC distinguished between the number of installations inside and outside the United States was 1968. After 1983, the survey was reorganized in a manner that made it incomparable with earlier years. Over the entire sixteen year period, this data concerns the installed base of over 350 different computer systems, with over half introduced after 1968 . This is clearly the best data available on the size of installed base of large computer systems in the United States. $^{24}$

\section{a. The Sample of systems}

IDC's definition of a mainframe contains two biases. First, the 1968 and 1969 definition of a mainframe is too broad. It includes some systems that IDC reclassified as "Digital Dedicated Application" in 1970. These systems are actually minicomputers, like the DEC PDP-8, not general-purpose systems. Second, redefinition problems arise once IDC establishes several on going databases for systems other than mainframes (i.e., minicomputers, small business systems, desktop). Its researchers occasionally move a system into the mainframe category that was not previously there. Its researchers also move a system out of the mainframe category that previously was there. ${ }^{25}$ In addition, IDC revised its survey scope twice, once between 1969 and

estimates comparable with Phister's [1979] and Flamm's [1987a,b] description of the diffusion of computing equipment, which used more aggregate IDC data. It also makes this paper comparable to Oliner's [1992] analysis of the retirement patterns among IBM mainframes, which uses similar data for IBM systems.

${ }^{24}$ Chow [1967], Michaels [1979], Phister [1979], Flamm [1987a,b], Dulberger [1989], Oliner [1992], Khanna [1994], Greenstein [1994], [1996] have used parts of this data and none have ever exploited all facets of it. See appendix of Greenstein [1994], [1996].

25 The most important case is IDC's decision to include the IBM System 36 in the sample in 1976 (estimated installed base at 5000 units) and exclude it from mainframes after that (but include it in "small business systems"). 
1970, and once between 1976 and 1977. In both cases, IDC reduced the number of models covered. ${ }^{26}$

The best solution to both problems defines the whole market consistently across different years of the sample. In this paper the boundary is set by a very small mainframe, something the size of an IBM 360/20. All systems smaller than what IDC calls size "2" are excluded. Fortunately, most of the reductions pertains to smaller systems which we exclude.

Finally, by the end of the sample, the difference between mainframes and some large general-purpose minicomputers (a.k.a. "superminis") becomes blurred, which raises questions about the survey's completeness. The main issue is whether IDC included in the mainframe category all the super-minicomputer systems that were close substitutes for general-purpose mainframes. A reasonable case could be made that IDC included most relevant systems, ${ }^{27}$ and a reasonable case could also be made that it did not. ${ }^{28}$ Ending the sample in 1983 and excluding small systems minimizes the problem.

\section{b. Definition of Model Failure and Independent Variables}

26 For example, the number of models covered in 1969 was 176 , while only 147 were covered in 1970 . In 1976 there were 205 models covered, but only 188 in 1977.

27 According to the 1983 IDC census for minicomputers and mainframes, the value of installed base associated with super-minicomputers came to roughly half the value of all minicomputers, or roughly 15 percent of the value of the installed base of mainframes. IDC's census differs from the other censuses, particularly CBEMA's [1992], because IDC includes several systems as mainframes (i.e., those from IBM) which others classify as superminicomputers. This makes IDC's census more complete by the early 1980s. For example, according to the CBEMA [1992], in 1976 mainframe shipments reached over 5 billion dollars, while the total spent on all minicomputers was 1.8 billion. By 1982, CBEMA estimates that mainframe shipments reached 10.6 billion and minicomputer shipments reached 7.7 billion. CBEMA does not state what fraction went to super-minicomputers, but 7.7 billion overstates the size of the competition between mainframe and minicomputers.

28 The most questionable omissions in IDC's mainframe tables are those regarding the VAX 11-780 models from DEC, and similar competitive models from other firms such as Prime, and Data General. 
In this study we use the installed base of systems to estimate the timing of product exit. Product exit is defined as the first year that a product's installed base does not increase. More specifically, we assume that exit occurs during the mid-point of this year. This is a reasonable measure of product obsolescence since this will be the first year in which retirements of the product are greater than the units sold. In addition, once a product's installed base begins to decline, the process never reverses itself. IDC usually begins tracking each product the year after its introduction. Following IDC, a model contributes an observation to our analysis in the first year that its installed base is above zero. Prior to that its installed base is zero.

While Phister [1979] clearly believes that IDC's estimates of installed base are the best available, he also warns about several potential problems that could influence calculations using these data. ${ }^{29}$ Dulberger also questions the accuracy of IDC's estimates of installed base, while conceding that they are the best publicly available. ${ }^{30}$ Given these concerns, the data was tested for internal consistency, a standard it readily met. ${ }^{31}$ In any event, no alternative is satisfactory. ${ }^{32}$ In our analyses of model failure rates, we included the following independent variables:

Year of Introduction (vintage): IDC provides the year and month of introduction for each

29 He states (pg. 250) "It is my opinion that IDC's staff, files, and data sources make that organization's published statistics the best available." Yet, due to occasional revisions of previous reports, Phister is not convinced that IDC's estimates of the size of installed base are precise. However, many of his uses of this data reveal his belief that IDC got the general order of magnitude correct. Where available, this paper uses Phister's corrections.

30 One especially difficult measurement problem is that IDC may underestimate the number of users who upgrade their systems (Dulberger, private communication).

31 The history of each new system was examined. Did the development of its installed base contain several years of growth followed by several years of decline? The presence of such a pattern make the data plausible.

32 Sales data is not available. It is not possible to estimate sales from the change in installed base from year to year, because IDC's estimates become an increasingly poor estimate of shipments of systems when systems become more than a few years old. 
system. The year is a product's vintage. Many industry observers believe that life cycles have been shortening in the computer industry. The inclusion of six dummy variables denoting the vintage of the system (in increments of two years) allows us to test this contention.

System Age: We also construct dummy variables for a system's age. Each dummy variable covers a one year increment with all product great than six years old lumped together. Using dummy variables allows us to capture nonlinear and non-monotonic patterns with respect to age. ${ }^{33}$

Firm Dummy Variables: We included firm dummy variables for IBM, NCR, Univac, Burroughs, CDC, General Electric (GEL), Honeywell, and RCA. We omit the Japanese firms and a few smaller mainframe suppliers.

System Size Class: IDC's censuses categorize every system by size, with size ranging from 2 to 7. This measure is categorical, not continuous, and is correlated with MIPS and memory. It provides our measure of a market niche, as the categories range from the highest and lowest ends of the computing spectrum. In our analysis, we analyze classes 4 through $7 .^{34}$ Previous analysis of this data shows that the average system in this sample got larger over time..$^{35}$

33 As noted in Berndt and Griliches [1993], we cannot simultaneously include year, vintage and age dummies. We include vintage and age because we have many other measures of market-based factors that change from one year to the next.

34 Size class 2 is omitted because IDC changed its definition of who was included in size class 2 in 1976 , making reliable counts of systems in that size class difficult to obtain. Because reliable counts of size class 2 systems could not be obtained, we could not obtain estimates of the number of systems in the lower adjacent size class for size class 3 systems. Thus, size class 3 systems were not included as endogenous variables.

35 In Greenstein [1994], which has data on popular systems, the typical system contains more memory (from 1099 to 5592 maximum memory on average) and performs more millions of instructions per second (from .326 to 2.22). The most dramatic changes occur in the last three years of the sample upon the entry of some large supercomputers. 
In some specifications we include dummy variables for size classes 5,6 and 7 , omitting 4 .

Numbers of Systems: We analyze the market structure underlying each market niche. The number of systems for sale within that niche indicates the substitutions available to buyers in that niche. This measures the degree of competitiveness of a market niche. For each system, we computed the number of systems for sale in a size class as well as in adjacent size classes. We also summed up the number of systems that were in nonadjacent size classes. ${ }^{36}$

Cannibalization: This variable became one when the firm introduces another newer product in an existing system's size class. Two other dummy variables, called cannibalization in an adjacent lower size class and cannibalization is a higher size class, are one when a firm introduced a newer system in an adjacent lower or higher size class, respectively. A firm's willingness to compete with itself within a size class with a new product indicates that the old product is approaching obsolescence. ${ }^{37}$

\section{c. Definition of Product Introductions and Independent Variables}

In our analysis of introductions, each firm contributes an observation in the first year that the firm has a product in that size class. ${ }^{38}$ A product introduction takes place when IDC records

36 We modeled this after sociological researchers, who have postulated that the intensity of competitive interactions between firms increases as the number of firms increases, ultimately resulting in lower firm founding rates and higher mortality rates (Hannan and Freeman [1977], [1989], Carroll [1984]).

37 If two systems are introduced in the same year we do not label this "cannibalization." We seek to measure when a firm replaces an existing model with a new design in the same product category.

38 In rare cases, a firm initially entered a size class but later is no longer selling systems in that size class. In that case, observations are still recorded for the firm in that size class, but we include a dummy variable indicating that the firm currently has no active products in the size class. We include a firm as long as at least one of the firm's products (or its decedents) sells. For example, we include GE until 1979 and RCA until 1977, when their last products ceased to sell under their new owners. 
it. We count the number of product introductions for each firm for each size class for each year.

Comparing market structure for entry and exit: We use many of the same variables as in the analysis of product exit, such as the number of systems in the focal size class, the number of systems in adjacent and nonadjacent size classes, size class dummy variables for sizes five through seven, and firm dummy variables for IBM, Univac, Honeywell, Burroughs, CDC, GEL and RCA. To control for any time trend, we also included dummy variables spaced every two years as covariates. The omitted years were 1969 and 1970. As with vintage, year correlates with many macro-economic changes, such as growth in income.

In addition, in some specifications we included the following variables:

Time since Last Innovation in Size Class: This variable is simply the time elapsed since a firm last introduced a new model in the size class. This may indicate how far the firm's product line in this size class is from the technical frontier.

No Models in Size Class: This is included as a control variable in the product introduction analysis. It is a dummy variable that is one if a firm has no sales in a size class in which it had previously introduced a product. It is zero otherwise. If a firm no longer has products in a size class, it may have decided not to compete further in that niche. This controls for the possibility that the decision to reenter a size class (in which a firm is no longer active) differs from the decision to introduce products in a class in which the firm is currently active.

\section{Description of Results}

In Table 1 we investigate unconditional life cycles each year by cohort. If product life cycles are shortening more recent cohorts would have a higher cumulative percentage of systems that have failed at each age. However, no clear pattern emerges. For example, while $66 \%$ of the 
1968 cohort has failed after four years, only $17 \%$ of the 1975 cohort has exited the market. On the other hand, $50 \%$ of the 1976 cohort is no longer viable after four years. Apparently, other covariates besides age alone must cause model failure.

Figure 2 shows the proportion of surviving systems in each size class over time. A relatively small proportion of systems survive over six years. Size class 7 systems seem to have a survival advantage; a higher proportion of these systems survive over most of the age range. This is consistent with our earlier speculation that different market niches may be associated with different customer bases, different applications and possibly different upgrade and replacement cycles. Our more detailed multivariate analyses below will determine if this is the case.

Table 2 includes means and correlations for the variables in our analysis of product failure. There are no interesting strong correlations between our exogenous variables, except a moderate positive correlation between year and density. Age and cannibalization are weakly positively correlated with our endogenous variable, product failure, but the existence of many confounding effects makes this difficult to interpret. We conclude that there is no simple explanation for product failure in this industry. We need to estimate a multivariate model.

\section{a. Product failure}

Table 3 presents several specifications for our basic model of product life, showing how we arrive at our optimal specification. We show all the specifications to provide comparison with the entry analysis.

Specification 1 includes dummy variables denoting product age. Consistent with our 
expectations, systems are more likely to die as they get older. In fact, a system that is between three and four years old is almost three times as likely to fail as one that is between one and two years old. By the time a system is over six years old it is almost seven times as likely to fail. It is important to note that the effects of age do not appear to fit a specific functional form. The positive effect of age increases sharply up until systems are three years old, then stays relatively constant until an age of five years. After reaching five years the hazard rate remains approximately constant. Thus, using dummy variables for age ranges seems to have been a better choice than attempting to force the model to a more restrictive functional form.

Specification 2 adds dummy variables denoting a system's year of introduction, and a set of firm dummies. Surprisingly, contrary to many analysts predictions, a system's year of introduction had no impact on its probability of failure. Product life cycles do not seem to be shortening over time. Age continues to have a powerful positive impact on the failure rate.

Specification 3 investigates the effects of a system's size class on its failure rate. Larger systems are less likely to fail. More specifically, the failure rate of systems in size class 7 is $47 \%$ lower than systems of size class four. There are many possible explanations for these differences across niches, so Specification 4 investigates the role of market structure in each niche. It adds the number of products in a system's size class and cannibalization to the analysis. Interestingly, both cannibalization and density in size class have their expected positive effects on the failure rate, and the size class dummies are no longer significant. The effect of cannibalization is particularly notable in that cannibalization of a system increases the probability of failure almost three times. This seems to suggest that different cannibalization patterns in 
different market niches result in many of the differences between market niches.

Specification 5 drops the insignificant size dummies from the analysis. All other variables remain significant as in specification 4 . Specification 4 , which includes the size dummies, is not a significant improvement over specification 5 . Thus, specification 5 is a more parsimonious model. Specification 6 adds the number of models in the adjacent size classes to the analysis. In this specification all of the density variables have their expected positive effect on the failure rate. Interestingly, the coefficients for the number of systems in the adjacent size classes approximately equals the coefficient on the number of systems in a systems own size class. Thus, these estimates indicate that products faced substantial competition from products in surrounding size classes. Three of the dummy variables denoting a system's year of introduction also become significant in this specification after these densities are controlled for. Systems introduced in 1974 through 1981 have significantly lower chances of exit than those introduced earlier. These results suggest that product life cycles are not shortening over the period and provide limited evidence that product life cycles may be lengthening. Specification 7 adds the adjacent size class cannibalization variables. Although the adjacent cannibalization variables are positive, they are not significant. Apparently, only cannibalization in the same market niche affects failure rates. ${ }^{39}$

\footnotetext{
${ }^{39}$ In models that are not shown here we also separately added the Gross Domestic Product and the growth in the Gross Domestic product as exogenous variables. Inclusion of the Gross Domestic Product sharply reduced the significance of the Year of Birth dummy variables and the Gross Domestic Product Term was also insignificant. This result is not surprising, however, since Gross Domestic Product is highly correlated with Calendar Year. Because product age and year of birth are already included in these models, including calendar year is redundant and it is not possible to estimate the model.
} 
Table 4 translates specification 6 into a few simple summary statistics. Since the model is multiplicative, one can calculate the multiplier of the hazard rate for a system under different conditions. For example, we can compare the hazard rate for a new system (zero years old) compared with a system that is between three and four years old. The older system is 4.71 times more likely to exit the market. ${ }^{40}$ This table identifies the most important covariates for product life. Age strongly predicts, and year of birth weakly predicts product exit. Holding all else constant, a model introduced in 1968 or 1969 is over 7 times more likely to exit than a model introduced from 1978 to 1979 . Similarly a model that is over six years old is 11.7 times as likely to fail as a newly introduced model.

As can be seen, density of substitute products also has an important effect, especially at the extremes. Since density of competition gradually grows over time, this effect increases in our data (see Figure 3). Cannibalization and firm effects will also induce product failure, but we note that these effects are relatively similar in magnitude to the effects from less-extreme variation in our continuous variables -- age, year, density and so on. Interestingly, IBM's products, as well as those of RCA, have the second highest rates of failure.

\section{b. Product introductions}

Table 5 shows means and correlations for the variables in our analysis of product entry. There are no strong correlations between our exogenous variables, except a moderate positive correlation between year and density. None of the exogenous variables correlated with product

\footnotetext{
40 This is calculated by taking the exponential of the difference in the exogenous variable times the coefficient.
} 
entry. We conclude that we need to estimate a multivariate model such as the Poisson model.

We first plotted the frequency distribution of the endogenous variable in a histogram.

Figure 4 shows that the data appear to fit a Poisson distribution. Using a Kolmogorov-Smirnov test we find that we cannot reject the null hypothesis, namely that the count of product introductions is Poisson distributed $(\mathrm{p}<.992)$. Furthermore, for all the specifications discussed below, we tested for over dispersion by rerunning all models using the negative binomial. Using a log ratio test, the test value never exceeded the critical value of 3.84 for any of our key models. Thus, the Poisson model appears to be a good model for these data.

As we did with Table 3, Table 6 presents several specifications of the rate at which firms introduced new models in each size class. Specification 1 shows that calendar time has little effect. Firms are slightly more likely to introduce new models between 1981 and 1982 than they are at the beginning of the time period. While the estimates monotonically increase over time after 1972, the general lack of significant differences between the dummies provides only weak evidence, at best, that product introductions accelerated over time. We also find that IBM, NCR, Honeywell, and CDC are slightly more likely to introduce new products than other firms.

Specification 2 reestimates specification 1 but adds the size class dummies to the analysis. Size class 4 is the source of more product introductions. Only the difference between size class 4 and size classes 5 and 6 is significant, however. Specification 3 adds the time since the last product introduction, a control for having no current models active in a size class, and the number of products in a size class. The effect of the number of models in a size class is negative 
and significant, suggesting that increased competition from substitutes deterred entry. In addition, in this specification firms are more likely to introduce new products between 1979 and 1982 than in earlier periods. Finally, Specification 4 attempts to learn whether the structure of each niche influences entry rates between niches. We see that none of the additional variables for market structure have a significant impact on product entry. ${ }^{41}$ Thus, specification 3 is the most parsimonious specification.

Using specification 3, Table 7 calculates the multiplier on the average rate of product introductions under varying conditions. As can be seen, products are increasingly more likely to be introduced after 1977 as compared to the rate of introductions in 1968 and 1969 , though the lack of statistical significance in some of the underlying coefficients adds caution to this observation. Table 7 also shows that firms are most likely to introduce products in size class 4 . Competition in a size class also has an effect on the entry rate. Products are 6.7 times more likely to be introduced when the number of products is 6 than when the number of competing products in a market niche is 32 (the maximum in our sample). Firm effects also play a part in predicting rates of product introductions. IBM, NCR, Honeywell, and Control Data are approximately equally likely to introduce new products. All of these firms, however, introduce products at a higher rate than the remaining firms. For instance, IBM is over two times as likely to introduce a new product as RCA and its decedents (RCA sold their division, which was operated by Univac for many years).

41 We also separately added Gross Domestic product and the growth in the Gross Domestic Product to these specifications but it did not affect the results. 


\section{Discussion and interpretation}

The results shed some light on the questions raised in section 2. Below we revisit these questions and discuss their interpretation.

Q1. Does entry or exit differ across years? Our results indicate that, contrary to expectations, product life cycles are not shortening over time in the mainframe market. ${ }^{42}$ In fact, once time varying covariates are controlled for, products that were introduced more recently tend to have longer expected life spans. There is limited evidence that after 1973 the rate of product introductions increases. These two results together suggest a gradual improvement in anticipated and realized post-entry conditions across all market niches, either from secular declines in costs or secular increases in demand. This may reflect the development and maturity of the mainframe computer industry. Support products such as software became available for more recent products. Design conventions and distribution channels also were widely understood.

Q2. Does the age of a product have any relationship to entry and exit? As products age their probability of exiting the market increases. Products that are over six years old are five times more likely to exit the market in the following year than products that are one year old. As products age they fall further behind the technological frontier and fewer buyers demand them. Interestingly, the pattern does not appear to be linear. Systems between 3 and 5 years old have approximately equal chances of failure, as do systems that are greater than five years old (albeit at a higher rate). The findings are more limited in the preferred specification of entry of new

42 We suspect that some of this belief comes from comparing product-life cycles across classes of computers. In other words, product life cycles are almost certainly shorter in minicomputer and shorter still in microcomputers. That, however, does not mean that mainframes changed their patterns over time. 
products. Entry is predicted by time since a firm last introduced a product. Since the coefficient estimate changes in different specifications, this does not seem to be a strong result. It weakly suggests that the timing of entry is influenced by factors other than the state of technology in a market niche.

Q3. Does entry or exit differ across firms? We find much evidence that product life cycles differ across vendors. For example, we find that IBM's market dominance did not lead to longer survival rates for its products. In fact, as can be seen from specification 6 of Table 3 and Table 4, IBM products tended to have higher failure rates than other vendors except GE. We find that Burroughs and CDC have the lowest product failure rates. Since these two firms had very different marketing strategies in this time period (one focused on mainstream business computing, the other on scientific computing), it is hard interpret this finding. As for entry behavior, GE and RCA, both of whom sold off their product lines to other firms after exiting in the early 70 s, have the lowest rate of entry. The entry of products associated with GE and RCA reflects the unwillingness of the new owners (Honeywell and Univac, respectively) to invest in those product lines after their purchase. IBM, NCR, Honeywell and CDC have relatively higher entry rates, a result that is consistent with the industry's perception that each of them was reasonably -- though not spectacularly -- profitable during this time period.

We now view these findings together. There is a small negative correlation $(-.41)$ between the firm coefficients from the two preferred specifications (specification 6 and 3 in Table 3 and Table 6, respectively). That is, the firms who enter with more products, all other things equal, also exit less often. The correlation is stronger $(-.55)$ among the non-IBM firms. This correlation may be seen in the following categorization of firm heterogeneity: IBM is the only firm with 
both high entry and exit rates. All the other firms with high entry rates, CDC, NCR, and Honeywell also have relatively low exit rates. GE and RCA are the only firms with both low entry and high exit rates. Burroughs (average entry rates, very low exit rates), Univac and the omitted firms (average in both entry and exit) are harder to characterize. No firm has both low entry and low exit rates.

Our statistical methods can only identify that these differences between firms exist, not why they occurred. Thus, we are very hesitant to attribute these differences to specific features of these firms, their efficiencies, or stated strategies. ${ }^{43}$ That said, the two known commercial failures, GE and RCA, display patterns in line with their historical reputation. In addition, the result for IBM is quite suggestive that IBM could and did use is preeminent position to have a distinct product-line strategy -- more new products, more experimentation (or less cautious product entry), inviting a mix of some successes and more failures. In addition, there are considerable differences among the non-IBM firms; CDC, Honeywell and NCR appear to display the patterns of relatively successful firms, even after controlling for other factors.

Q4: Does market niche predict entry or exit? We find evidence that product exit differs across market niches and mixed evidence that product entry differs across niches. Controlling only for age and firm, it appears that the larger the size class the lower the rate of exit. On further investigation, much of this seems attributable to cross-niche differences in cannibalization and competition densities (see below). Entry behavior seems to differ across niches, but the only robust inference across all specifications is that the smallest niche has higher rates of entry.

43 For example, our sample ends before the Japanese firms fully developed their product lines in the $1980 \mathrm{~s}$. 
Putting the findings for entry and exit together, there is simply not sufficient evidence in favor or against the view that racing behavior was more severe at the technological frontier at the highest end of the computing market. Nor is there sufficient evidence to conclude that competition from smaller systems had an appreciable effect on smaller system entry and exit.

Q5. How does the number of competitors influence entry and exit? Exit rates are influenced by competition from within a product's size class as well as from competition in surrounding niches. Importantly, the effects of the size class dummies become insignificant. Only competition within a niche has a statistically significant effect on the rate at which firms introduce new products.

Q6: Does cannibalization influence product turnover? Our statistical estimates show that cannibalization does predict product exit. Once a firm introduces a new product in a size class, other products from that firm in that niche are more likely to exit. We offer two interpretations, one in which entry of cannibalization is random and one it which it is not. If entry is random, then cannibalization tells us about competition between two products from the same firm. Those two products probably share many similar features, so it would not be surprising to see competition between them lead to exit of the older one. If entry is not random at all, as in a market in which firms can reasonably predict obsolescence of existing products, the timing of obsolescence will be endogenous. Firms will try to cannibalize when their existing products are close to losing commercial viability. In that case the coefficient on cannibalization measures otherwise unmeasured obsolescence. Available evidence as yet does not allow us to distinguish between these two interpretations. Finding a way to do so is a key issue for future research on product life cycles. 
Q7: Do the same factors predict entry and exit? The evidence does not point toward a strong relationship between the factors that predict entry and exit, but it also does not suggest that there is no relationship. There is weak evidence that the year of introduction influences both entry and exit. The importance of cannibalization also points toward a more systemic relationship between entry and exit, but this interpretation has unresolvable ambiguities. There is some evidence that there are differences in entry and exit across niches, but we cannot attribute all these differences to market structure within a niche. While competition within a niche impacts both entry and exit, competition from surrounding niches only affects the exit rate.

These findings together do not suggest a strong relationship, though not a complete absence of one either, between the determinants of entry and exit. On the one hand, if managers of firms are aware of the factors that lead to longer product survival rates, they should attempt to strategically introduce their products to take advantage of extended life cycles. On the other hand, it is quite plausible for the variables which influence product survival rates to only have a weak relationship with product introductions. ${ }^{44}$

\section{Conclusion}

The product life-cycle should be the focus of attention in dynamic industries. In mainframe computing, at the very least, this is where many interesting market events took place

\footnotetext{
44 Many researchers have also suggested that there are substantial barriers to purposeful actions by firms, especially those conducted in high technology research and development (Hannan and Freeman [1977], [1984]). Because of bounded rationality, prediction error, difficulties in managing the timing of production innovation and resolving other technical problems, managers may not be able to formulate and execute strategies that optimize the timing of product introductions. Also, we have the benefit of hindsight, perceiving relationships that were unfolding as crucial product design decisions were made years ago, possibly before these relationships were understood by decision makers.
} 
between the late 1960s and 1970s. Products turned over frequently and diffused new technical capabilities to user in new designs.

In this study, we tried to show the value of bringing statistical techniques to measuring the determinants of the entry and exit of new products. We tried to move beyond (now) standard hedonic methods. Our approach allowed us to measure the importance of different features of market structure for product entry and exit, especially as that structure changes over time or varies across product niches.

We found that several features of market structure predict product introductions and exit. Later vintage products do not have shorter lives. Entry also weakly increases over time. We find strong evidence of differences between firms in their product life cycle behavior. We also find evidence of differences between niches in product life cycles. Cannibalization within a market niche decreases a product's life, but cannibalization in "neighboring" niches has little influence. Competition from products within a niche and surrounding niches have a significant impact on a product's exit, but only within niche competition has an effect on new entry. We conclude that some of the economic factors shaping a product's exit have a similar influence on product entry and some do not. We think this latter issue is an important one and worthy of further investigation in other markets.

We believe that these findings illustrate the value of analyzing the separate components of product life cycles --- in this study, rates of product introduction and exit. This motivates further work to establish links between different aspects of the product life-cycle -- entry, growth, market share, exit from sales, and user retirement.

We believe that future work should try to develop structural models of firm behavior -- 
i.e., models that account for product line strategies, different racing behavior in different niches, technical and marketing uncertainty prior to the introduction of a new design. Such models can help develop the links between product entry and survival as new markets mature. Until these models are further developed, which we expect will be a long and difficult empirical agenda, we find it useful to develop statistical methods at the product level, characterize the essential long run patterns, and interpret these patterns in light of well known questions, as we did in this paper.

There are many product markets, especially within electronics, in which product level turnover lies behind embodied technical change. Fax-machines, disk-drives, PCS, routers and switches, printers, micro-processors and shrink-rapped software, just to name a few cases, all lend themselves to analysis at the level of the product. We have taken the first steps in this agenda. 


\section{Bibliography}

Berndt, E.R. and Griliches, Z. [1993], "Price indices for Microcomputers: An Exploratory Study." in (Eds) Murray Foss, Marylin Manser, and Allan Young, Price Measurement and their Uses, University of Chicago Press, Chicago.

Bresnahan, T. and Greenstein, S., [1995]. "Technological Competition and the Structure of the Computer Industry," CEPR Discussion Paper No. 315, Stanford University, June 1992.

Bresnahan, T. and Greenstein, S., [1997], "Technical Progress and Co-Invention in Computing and in the Uses of Computers," Brookings Papers on Economic Activity, Microeconomics, January, pp. 1-72.

Cameron, A. and Trevedi, P., [1986] "Econometric Models Based on Count Data: Comparisons and Applications of Some Estimators and Tests," Journal of Applied Econometrics. 1: $29-53$.

Carroll, G.R. [1983] "Dynamic Analysis of Discrete Dependent Variables: A Didactic Essay" Quality and Quantity, 17, 425-460

Carroll, G.R. [1984], "Organizational Ecology" Annual Review of Sociology. 10:71-93

CBMEA [1992], Computer Business Manufacturing and Equipment Association, Information Technology Industry Databook, 1992, Washington, D.C.

Chow, G. C., [1967], "Technological Change and the Demand for Computers," American Economic Review, Vol 57, 5, December, pp. 117-1130.

Cole, R., Chen, Y. C. , Barquin-Stolleman, Y. C., Dulberger, E., Helvacian, N., Hodge, J., [1986], "Quality Adjusted Price Indexes for Computer Processors, Selected Peripheral Equipment," Survey of Current of Business 66 (Jan), PP 41-50.

Dulberger, E.R. [1989], "The Application of a Hedonic Model to a Quality-Adjusted Price Index for Computer Processors." In D.W. Jorgenson \& R. Landau (eds.), Technology and capital formation. Cambridge, MA: The MIT Press.

Fisher, Franklin M., James W. McKie and Richard B. Mancke [1983], IBM and the U.S. Data Processing Industry: An Economic History, New York: Praeger Publishers.

Fisher, Franklin M. and McGowan, John J., and Greenwood, Joen E. [1983], Folded, Spindled, and Mutilated: Economic Analysis and U.S. vs. IBM, MIT Press, Cambridge Mass. 
Flamm, K. [1987a], Targeting the Computer: Government Support and International Competition, Washington D.C.: The Brookings Institute.

Flamm, Kenneth [1987b], Creating the Computer: Government, Industry, and High Technology, Washington D.C.: The Brookings Institute.

Friedman, A. L., and Cornford D.S. [1989], Computer Systems Development: History, Organization and Implementation, John Wiley and Sons, New York, NY.

Gordon, R. J. [1989], "The Postwar Evolution of Computer Prices," in Technology and Capital Formation, Edited by Dale W. Jorgenson and Ralph Landau, MIT Press.

Gort, M. and Klepper, S. [1982], "Time Paths in the Diffusion of Product Innovations,"Economic Journal, 92, 630-653

Greenstein, S. [1996], "From Super-minis to Super Computers: Estimating Surplus in the Computing Market." in (Eds) Tim Bresnahan and Robert J. Gordon, The Economics of New Products, National Bureau of Economic Research, University of Chicago Press.

Greenstein, S. [1994], "Did Computers Diffuse Quickly? Best Versus Average Practice in Mainframe Computers, 1968-1983." Working Paper No. 4647, National Bureau of Economic Research, Cambridge, MA. February.

Hannan, M. and Freeman, J.[1977], "The Population Ecology of Organizations" American Journal of Sociology, 82, 929-964.

Hannan, M. and Freeman, J.[1984], "Structural Inertia and Organizational Change" American Sociological Review 49, 149-164.

Hannan, M. and Freeman, J. [1989], Organizational Ecology, Cambridge, MA: Harvard University Press.

Hartman, Raymond S. and Teece, David J. [1990], "Product Emulation Strategies in the Presence of Reputation Effects and Network Externalities: Some evidence form the Minicomputer Industry," Economics of Innovation and New Technology.

Inmon, William H. [1985], Technomics: The Economics of Technology \& the Computer Industry, Dow Jones-Irwin.

Jovanovic, Boyan, and Glenn M MacDonald [1994a], "Competitive Diffusion," Journal of Political Economy, 102 (1), February, pp. 24-52.

Jovanovic, Boyan, and Glenn M MacDonald [1994b], "The Life Cycle of a Competitive 
Industry," Journal of Political Economy, 102 (1), April, pp. 322-347.

Khanna, Tarun. [1994]. "Racing Behavior: Technological Evolution in the High-end Computing Industry," Research Policy.

Klepper, S. [1996], "Entry, Exit, Growth, and Innovation over the Product Life Cycle.", American Economic Review, 86(3), pp. 562-583.

Klepper, S. and Graddy, E. [1990], "The Evolution of New Industries and the Determinants of Market Structure" Rand Journal of Economics, 21, 27-44.

Michaels, Robert [1979], "Hedonic Prices and the Structure of the Digital Computer Industry," Journal of Industrial Economics.

Oliner, S. [1992], Constant-Quality Price Change, Depreciation, and Retirement of Mainframe Computers. Manuscript from the Board of Governors of the Federal Reserve System, Division of Research and Statistics.

Pakes, Ariel, and Paul McGuire [1994], "Computing Markov-perfect Nash Equilibria: numberical Implications of a Dynamic Differentiated Product Model," Rand Journal of Economics, 25 (4), Winter, pp 555-589.

Phister, Montgomery, Jr. [1979], Data Processing Technology and Economics, Digital Press, Santa Monica.

Reinganum, Jennifer [1989], "The Timing of Innovation: Research, Development and Diffusion" in (eds) Richard Schmalensee and Robert Willig, The Handbook of Industrial Organization, North Holland Press, New York.

Rosenberg, Nathan [1982], Inside the Black Box: Technology and Economics, Cambridge: Cambridge University Press.

Saloner, G., and Sheperd, A.[1996], "Adoption of Technologies with Network Effects: An Empirical Examination of the Adoption of Automated Teller Machines." Rand Journal of Economics, 26(3), Autumn, pp. 479-501.

Singh, J. and Lumsden, C.J. [1990], "Theory and Research in Organizational Ecology," Annual Review of Sociology 16: 161-195.

Stavins, Joanna [1996], "Estimating Demand and Supply in a Differentiated Product Industry: The Personal Computer Market," Review of Economics and Statistics, February.

Trajtenberg, M. [1990], Economic analysis of product innovation. Cambridge, MA: Harvard 
University Press.

Triplett, Jack E. [1986], "The Economic Interpretation of Hedonic Methods," Survey of Current Business, vol. 66, January.

Triplett, J. E. [1989], "Price and technological change in a capital good: A survey of research on computers." In D.W. Jorgenson \& R. Landau (eds.), Technology and Capital Formation. Cambridge, MA: The MIT Press.

Tuma, N.B. Invoking Rate [1980], Menlo Park, CA: SRI International 
FIGURE 1

\section{Products Entering and Exiting the Market}

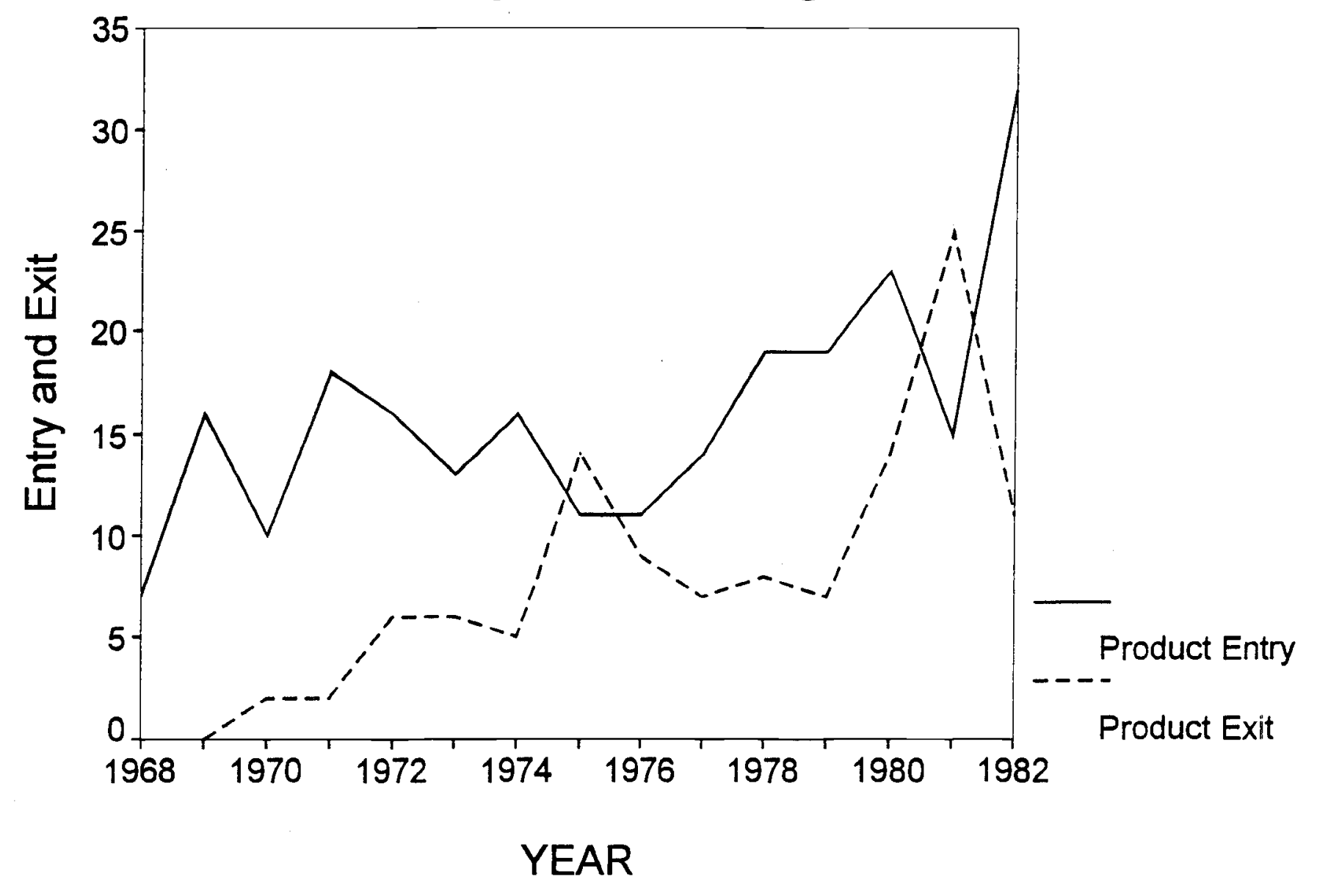


FIGURE 2 Kaplan Meier Survival Estimates

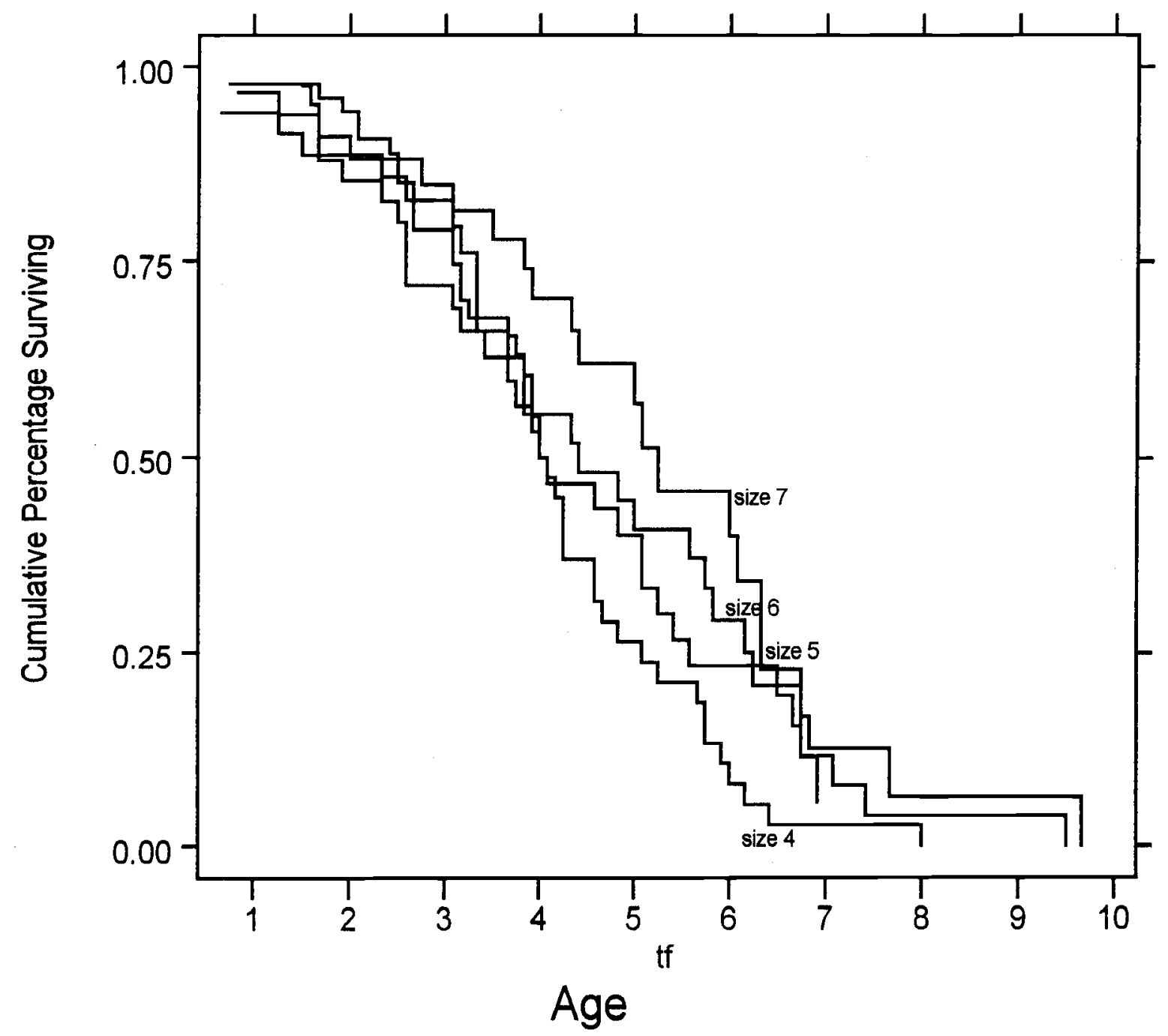


FIGURE 3

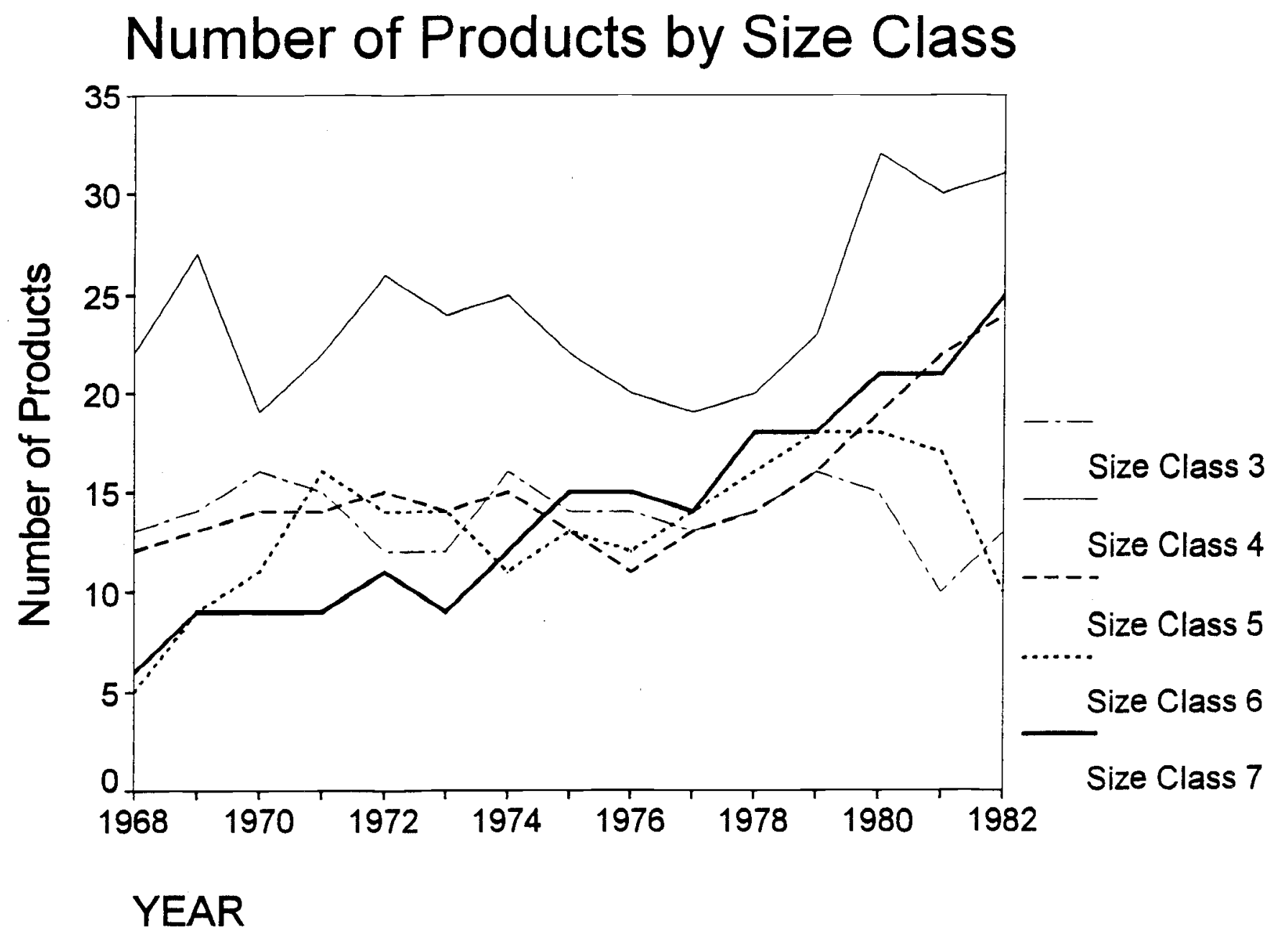


FIGURE 4

Frequencies of Model Introductions

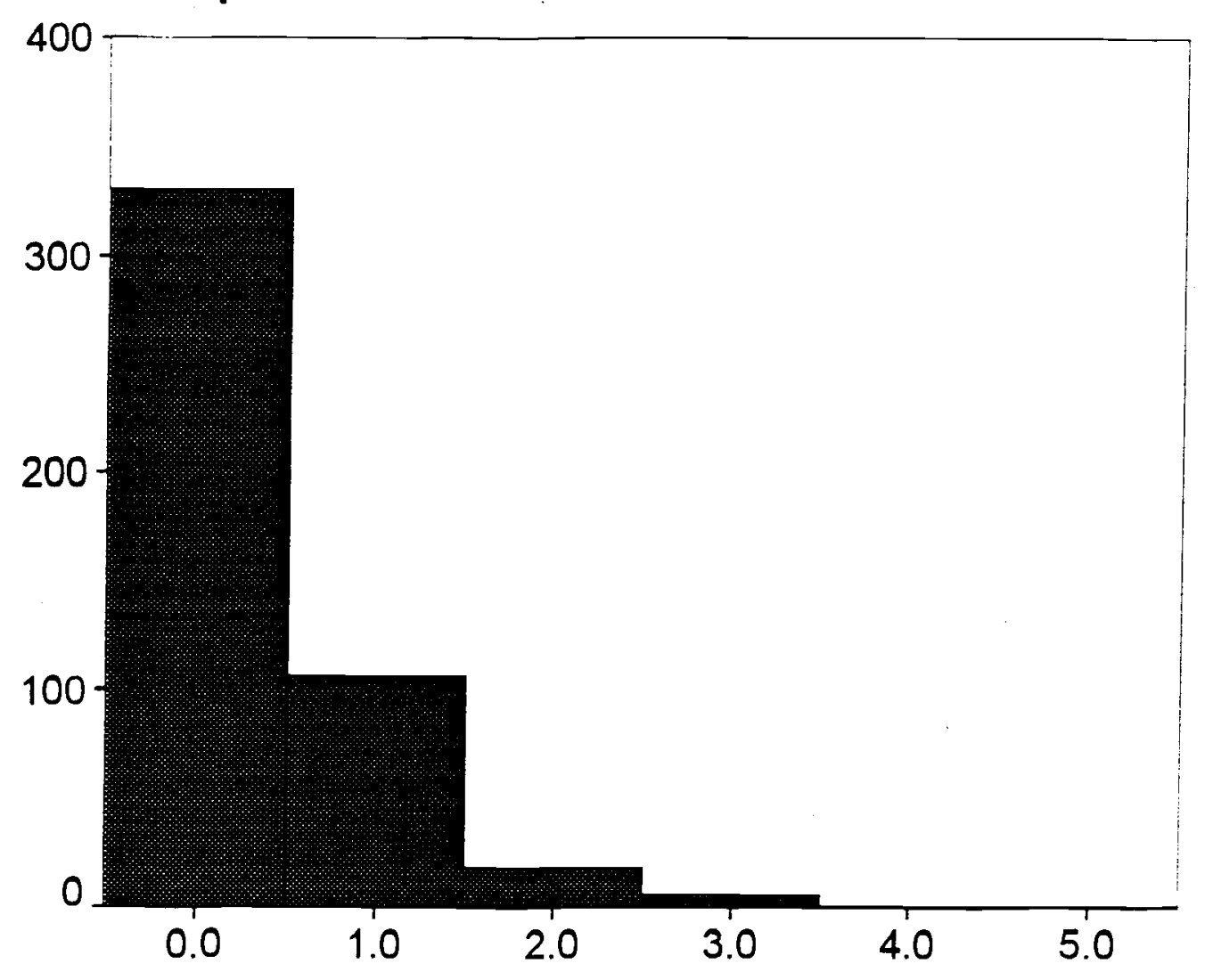

Number of Model Introductions 
TABLE 1

Cumulative Percentage Died by Cohort

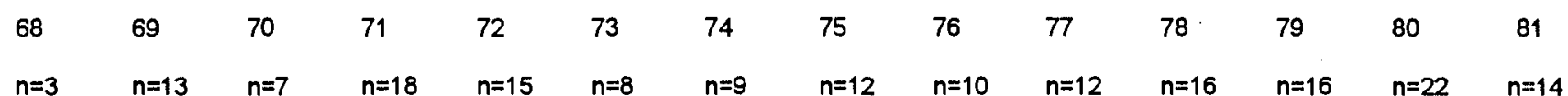

AGE

2

0

$15.4 \% \quad 14.2 \% \quad 0 \%$

$6.7 \%$

$0 \% \quad 16.7 \% \quad 0 \%$

$8.3 \%$

$0 \%$

$0 \% \quad 0 \% \quad 7.1 \%$

$23.1 \% \quad 42.8 \%$

$16.7 \% \quad 13.3 \% \quad 25 \%$

$11.1 \% \quad 16.7 \% \quad 10 \%$

$16.7 \% \quad 0 \%$

$12.5 \% \quad 18.2 \%$

3

$$
0 \%
$$

$46.2 \% \quad 42.8 \%$

$33.3 \% \quad 33.3 \% \quad 50 \%$

$11.1 \% \quad 16.7 \% \quad 10 \%$

$41.7 \% \quad 50 \%$

$25 \%$

4

$66.67 \% \quad 61.5 \% \quad 42$.

$66.7 \% \quad 53.3 \%$

$625 \%$

$33.3 \% \quad 16.7 \% \quad 50 \%$

$66.7 \% \quad 62.5 \%$

$$
100 \%
$$$$
69.2 \% \quad 57.1 \%
$$

$72.2 \%$

66.7

$62.5 \%$

$33.3 \% \quad 50 \%$

$90 \%$

$91.7 \%$

$\begin{array}{lllllllll}100 \% & 84.6 \% & 71.4 \% & 83.3 \% & 93.3 \% & 87.5 \% & 55.6 \% & 83.3 \% & 90 \%\end{array}$

$100 \% \quad 84.6 \% \quad 100 \%$

$88.9 \%$

$100 \%$

$100 \% \quad 100 \%$

83.3\%

$100 \% \quad 84.6 \% \quad 100 \% \quad 100 \% \quad 100 \% \quad 100 \% \quad 100 \%$

$100 \% \quad 92.3 \% \quad 100 \% \quad 100 \% \quad 100 \% \quad 100 \%$

$100 \% \quad 100 \% \quad 100 \% \quad 100 \% \quad 100 \%$ 
TABLE 2

Means, Standard Deviations, and Correlations for Mainframe Product Failure Analyses

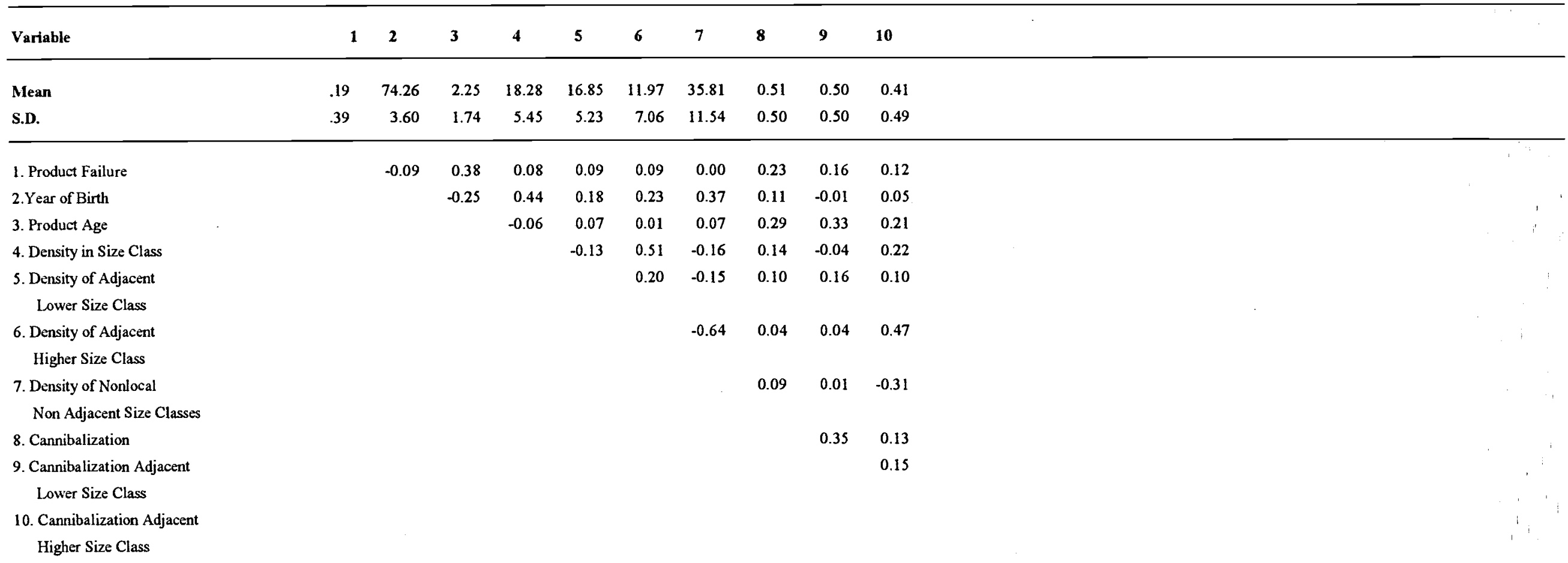


Table 3

Models of Mainframe Product Failures: 1969-1982

\begin{tabular}{|c|c|c|c|c|c|c|c|}
\hline & (1) & (2) & (3) & (4) & (5) & (6) & (7) \\
\hline Constant & $\begin{array}{r}-3.13^{\star * *} \\
(.354)\end{array}$ & $\begin{array}{r}-3.31^{* *} \\
(.524)\end{array}$ & $\begin{array}{r}-3.04^{* *} \\
(.549)\end{array}$ & $\begin{array}{r}-5.28^{* *} \\
(.982)\end{array}$ & $\begin{array}{r}-4.23^{* *} \\
(.630)\end{array}$ & $\begin{array}{l}-7.74^{* *} \\
(1.20)\end{array}$ & $\begin{array}{l}-7.74^{* \star} \\
(1.20)\end{array}$ \\
\hline Age between 1 and 2 Years & $\begin{array}{l}1.04^{\star \star} \\
(.425)\end{array}$ & $\begin{array}{l}1.05^{\star \star} \\
(.426)\end{array}$ & $\begin{array}{l}1.05^{* *} \\
(.426)\end{array}$ & $\begin{array}{r}.805^{*} \\
(.431)\end{array}$ & $\begin{array}{l}.835^{*} \\
(.430)\end{array}$ & $\begin{array}{c}.743 \\
(.436)\end{array}$ & $\begin{array}{c}.714 \\
(.443)\end{array}$ \\
\hline Age between 2 and 3 Years & $\begin{array}{l}1.64^{* *} \\
(.408)\end{array}$ & $\begin{array}{l}1.72^{* *} \\
(.426)\end{array}$ & $\begin{array}{l}1.73^{\star \star} \\
(.426)\end{array}$ & $\begin{array}{l}1.30 * * \\
(.437)\end{array}$ & $\begin{array}{l}1.36^{\star *} \\
(.434)\end{array}$ & $\begin{array}{l}1.17^{\star *} \\
(.446)\end{array}$ & $\begin{array}{r}1.12^{* *} \\
(.462)\end{array}$ \\
\hline Age between 3 and 4 Years & $\begin{array}{l}2.10^{* *} \\
(.406)\end{array}$ & $\begin{array}{l}2.29^{* *} \\
(.427)\end{array}$ & $\begin{array}{l}2.34^{* *} \\
(.429)\end{array}$ & $\begin{array}{l}1.78^{* *} \\
(.444)\end{array}$ & $\begin{array}{l}1.86^{* \star} \\
(.438)\end{array}$ & $\begin{array}{l}1.55^{* *} \\
(.454)\end{array}$ & $\begin{array}{c}1.49^{* *} \\
(.471)\end{array}$ \\
\hline Age between 4 and 5 Years & $\begin{array}{l}2.21^{* *} \\
(.429)\end{array}$ & $\begin{array}{l}2.51^{* *} \\
(.455)\end{array}$ & $\begin{array}{l}2.58^{* *} \\
(.458)\end{array}$ & $\begin{array}{l}1.88^{* *} \\
(.477)\end{array}$ & $\begin{array}{l}2.00^{* *} \\
(.468)\end{array}$ & $\begin{array}{l}1.60^{* *} \\
(.485)\end{array}$ & $\begin{array}{l}1.54^{* *} \\
(.500)\end{array}$ \\
\hline Age between 5 and 6 Years & $\begin{array}{l}2.76^{* *} \\
(.429)\end{array}$ & $\begin{array}{l}3.14^{* *} \\
(.460)\end{array}$ & $\begin{array}{l}3.23^{* *} \\
(.464)\end{array}$ & $\begin{array}{l}2.47^{\star *} \\
(.486)\end{array}$ & $\begin{array}{l}2.62^{* *} \\
(.474)\end{array}$ & $\begin{array}{l}2.04^{* *} \\
(.505)\end{array}$ & $\begin{array}{l}2.00^{* *} \\
(.516)\end{array}$ \\
\hline Age greater than 6 Years & $\begin{array}{l}2.95^{\star \star} \\
(.449)\end{array}$ & $\begin{array}{l}3.39^{* *} \\
(.490)\end{array}$ & $\begin{array}{l}3.52^{* *} \\
(.497)\end{array}$ & $\begin{array}{l}3.04^{* *} \\
(.499)\end{array}$ & $\begin{array}{l}3.19^{n *} \\
(.490)\end{array}$ & $\begin{array}{l}2.46^{* *} \\
(.538)\end{array}$ & $\begin{array}{l}2.40^{* *} \\
(.550)\end{array}$ \\
\hline Born in 1970 to 1971 & & $\begin{array}{l}-.155 \\
(.375)\end{array}$ & $\begin{array}{l}-.169 \\
(.382)\end{array}$ & $\begin{array}{l}-.344 \\
(.384)\end{array}$ & $\begin{array}{l}-.388 \\
(.387)\end{array}$ & $\begin{array}{l}-.426 \\
(.378)\end{array}$ & $\begin{array}{l}-.427 \\
(.389)\end{array}$ \\
\hline Born in 1972 to 1973 & & $\begin{array}{c}.133 \\
(.349)\end{array}$ & $\begin{array}{c}.202 \\
(.362)\end{array}$ & $\begin{array}{l}-.223 \\
(.359)\end{array}$ & $\begin{array}{l}-.121 \\
(.349)\end{array}$ & $\begin{array}{l}-.126 \\
(.352)\end{array}$ & $\begin{array}{l}-.144 \\
(.359)\end{array}$ \\
\hline Born in 1974 to 1975 & & $\begin{array}{l}-.583 \\
(.366)\end{array}$ & $\begin{array}{l}-.437 \\
(.378)\end{array}$ & $\begin{array}{l}-.923^{* *} \\
(.385)\end{array}$ & $\begin{array}{l}-.912^{\star *} \\
(.364)\end{array}$ & $\begin{array}{r}-1.55^{* *} \\
(.460)\end{array}$ & $\begin{array}{r}-1.58^{* *} \\
(.473)\end{array}$ \\
\hline Born in 1976 to 1977 & & $\begin{array}{l}.480 \\
(.363)\end{array}$ & $\begin{array}{l}.398 \\
(.362)\end{array}$ & $\begin{array}{l}-.0956 \\
(.377)\end{array}$ & $\begin{array}{l}-.0344 \\
(.369)\end{array}$ & $\begin{array}{l}-1.05^{* *} \\
(.493)\end{array}$ & $\begin{array}{l}-1.05^{* *} \\
(.498)\end{array}$ \\
\hline Born in 1978 to 1979 & & $\begin{array}{l}.079 \\
(.398)\end{array}$ & $\begin{array}{l}.210 \\
(.412)\end{array}$ & $\begin{array}{l}-.787 \\
(.477)\end{array}$ & $\begin{array}{l}-.595 \\
(.423)\end{array}$ & $\begin{array}{l}-1.99^{\star *} \\
(.609)\end{array}$ & $\begin{array}{l}-2.00^{* *} \\
(.613)\end{array}$ \\
\hline Born in 1980 to 1981 & & $\begin{array}{l}.293 \\
(.579)\end{array}$ & $\begin{array}{l}.263 \\
(.589)\end{array}$ & $\begin{array}{l}-.945 \\
(.670)\end{array}$ & $\begin{array}{l}-.722 \\
(.633)\end{array}$ & $\begin{array}{l}-2.17^{* *} \\
(.773)\end{array}$ & $\begin{array}{l}-2.18^{\star *} \\
(.782)\end{array}$ \\
\hline IBM & & $\begin{array}{l}.451 \\
(.363)\end{array}$ & $\begin{array}{l}.513 \\
(.366)\end{array}$ & $\begin{array}{l}.422 \\
(.373)\end{array}$ & $\begin{array}{l}.364 \\
(.369)\end{array}$ & $\begin{array}{l}.409 \\
(.373)\end{array}$ & $\begin{array}{l}.372 \\
(.377)\end{array}$ \\
\hline NCR & & $\begin{array}{l}.287 \\
(.457)\end{array}$ & $\begin{array}{l}.046 \\
(.470)\end{array}$ & $\begin{array}{l}-.042 \\
(.479)\end{array}$ & $\begin{array}{l}-.126 \\
(.470)\end{array}$ & $\begin{array}{l}.0244 \\
(.472)\end{array}$ & $\begin{array}{l}-.0253 \\
(.480)\end{array}$ \\
\hline UNI & & $\begin{array}{l}-.144 \\
(.379)\end{array}$ & $\begin{array}{l}-.152 \\
(.385)\end{array}$ & $\begin{array}{l}-.142 \\
(.390)\end{array}$ & $\begin{array}{l}-.140 \\
(.389)\end{array}$ & $\begin{array}{l}-.191 \\
(.385)\end{array}$ & $\begin{array}{l}-.202 \\
(.392)\end{array}$ \\
\hline HON & & $\begin{array}{l}.288 \\
(.324)\end{array}$ & $\begin{array}{l}.179 \\
(.332)\end{array}$ & $\begin{array}{l}-.0726 \\
(.342)\end{array}$ & $\begin{array}{l}-.0758 \\
(.335)\end{array}$ & $\begin{array}{l}-.101 \\
(.340)\end{array}$ & $\begin{array}{l}-.122 \\
(.348)\end{array}$ \\
\hline BUR & & $\begin{array}{l}-.602 \\
(.367)\end{array}$ & $\begin{array}{l}-.648^{\star} \\
(.369)\end{array}$ & $\begin{array}{l}-.819^{* \star} \\
(.375)\end{array}$ & $\begin{array}{l}-.816^{\star *} \\
(.374)\end{array}$ & $\begin{array}{l}-.836^{\star *} \\
(.373)\end{array}$ & $\begin{array}{l}-.866^{* *} \\
(.378)\end{array}$ \\
\hline $\operatorname{CDC}$ & & $\begin{array}{l}-.089 \\
(.336)\end{array}$ & $\begin{array}{l}-.064 \\
(.343)\end{array}$ & $\begin{array}{l}-.230 \\
(.351)\end{array}$ & $\begin{array}{l}-.272 \\
(.349)\end{array}$ & $\begin{array}{l}-.273 \\
(.346)\end{array}$ & $\begin{array}{l}-.265 \\
(.354)\end{array}$ \\
\hline GEL & & $\begin{array}{l}.226 \\
(.477)\end{array}$ & $\begin{array}{l}-.0601 \\
(.511)\end{array}$ & $\begin{array}{l}.647 \\
(.525)\end{array}$ & $\begin{array}{l}.447 \\
(.518)\end{array}$ & $\begin{array}{l}.717 \\
(.521)\end{array}$ & $\begin{array}{l}.768 \\
(.529)\end{array}$ \\
\hline RCA & & $\begin{array}{l}.293 \\
(.505)\end{array}$ & $\begin{array}{l}.436 \\
(.518)\end{array}$ & $\begin{array}{l}.317 \\
(.537)\end{array}$ & $\begin{array}{l}.446 \\
(.518)\end{array}$ & $\begin{array}{l}.413 \\
(.526)\end{array}$ & $\begin{array}{l}.484 \\
(.541)\end{array}$ \\
\hline
\end{tabular}

Standard errors are in parentheses. ${ }^{\star *} p<.05 .{ }^{\dagger} p<.10$. 
Table 3 Continued

Models of Mainframe Product Failures: 1969-1982*

(1)

(2)

(3)

(4)

(5)

(6)

(7)

Size Class 5

Size Class 6

Size Class 7

Density in Size Class

Density of Adjacent Lower Size Class

Density of Adjacent Higher Size Class

Density of Nonlocal-Nonadjacent

Size Classes

Cannibalization

Cannibalization Adjacent

Lower Size Class

Cannibalization Adjacent Higher Size Class

- Log Likelihood

- Log Likelihood (without covariates)

Likelihood Chi-squared Ratio

Degrees of Freedom

Number of Firm-Year Spells

Number of Events

\begin{tabular}{|c|c|c|c|c|}
\hline $\begin{array}{l}-.299 \\
(.254)\end{array}$ & $\begin{array}{c}.552 \\
(.393)\end{array}$ & & & \\
\hline $\begin{array}{l}-.496 \\
(.297)\end{array}$ & $\begin{array}{c}.699 \\
(.465)\end{array}$ & & & \\
\hline \multirow[t]{8}{*}{$\begin{array}{l}-.633^{* \star \star} \\
(.307)\end{array}$} & $\begin{array}{c}.237 \\
(.447)\end{array}$ & & & \\
\hline & $\begin{array}{l}.100^{* *} \\
(.037)\end{array}$ & $\begin{array}{l}.0604^{* *} \\
(.0213)\end{array}$ & $\begin{array}{c}.0784^{* *} \\
(.0256)\end{array}$ & $\begin{array}{c}.0798^{* *} \\
(.0258)\end{array}$ \\
\hline & & & $\begin{array}{c}.0688^{* *} \\
(.0212)\end{array}$ & $\begin{array}{c}.0676^{* *} \\
(.0215)\end{array}$ \\
\hline & & & $\begin{array}{c}.0722^{* *} \\
(.0272)\end{array}$ & $\begin{array}{c}.0713^{* *} \\
(.0296)\end{array}$ \\
\hline & & & $\begin{array}{c}.0515^{\star \star} \\
(.0187)\end{array}$ & $\begin{array}{l}.0513^{* *} \\
(.0188)\end{array}$ \\
\hline & $\begin{array}{l}1.01 * * \\
(.256)\end{array}$ & $\begin{array}{l}.956^{* \star} \\
(.252)\end{array}$ & $\begin{array}{l}.976^{* \star} \\
(.252)\end{array}$ & $\begin{array}{l}.952^{\star \star} \\
(.256)\end{array}$ \\
\hline & & & & $\begin{array}{l}.144 \\
(.245)\end{array}$ \\
\hline & & & & $\begin{array}{l}.007 \\
(.258)\end{array}$ \\
\hline 258.9 & 246.2 & 248.0 & 240.1 & 239.9 \\
\hline 313.3 & 313.3 & 313.3 & 313.3 & 313.3 \\
\hline 108.7 & 134.2 & 130.5 & 146.4 & 146.8 \\
\hline 23 & 25 & 22 & 25 & 27 \\
\hline 650 & 650 & 650 & 650 & 650 \\
\hline 122 & 122 & 122 & 122 & 122 \\
\hline
\end{tabular}

" Standard errors are in parentheses. *" $p<.05 . " p<.10$. 


\section{Table 4}

Effects of Changes in the Independent Variables on the Multiplier of the Rate of Product Exit"

Independent Variables

Change in Independent

Multiplier of the Rate

Variables

Of Product Exit

1. Cohort

2. Product Age

3. Density in Size Class

4. Density of Adjacent Lower Size Class

5. Density of Adjacent

Higher Size Class

6. Density of NonlocalNonadjacent Size Classes

7. Cannibalization

8. Firm Effects
Change from: $1974-1975$ cohort to $1968-1969$ cohort

Change from: $1976-1977$ cohort to $1968-1969$ cohort

Change from: $1978-1979$ cohort to $1968-1969$ cohort

Change from: $1980-1981$ cohort to $1968-1969$ cohort

Change from: 0 to between 1 and 2 years

Change from: 0 to between 2 and 3 years

Change from: 0 to between 3 and 4 years

Change from: 0 to between 4 and 5 years

Change from: 0 to between 5 and 6 years

Change from: 0 to greater than 6 years

Change from: 6 to 32

6 to 19

6 to 13

Change from: 6 to 32

6 to 19

6 to 13

Change from: 6 to 32

6 to 19

6 to 13

Change from: 18 to 66

18 to 46

18 to 32

Change from: 0 to 1

Change from: NCR to IBM

Univac to IBM

Honeywell to IBM

Burroughs to IBM

Control Data to IBM

General electric to IBM

RCA to IBM
4.71

2.86

7.32

8.76

2.10

3.22

4.71

4.95

7.69

11.7

7.68

2.77

1.73

5.99

2.45

1.62

6.54

2.56

1.66

11.83

4.22

2.05

2.65

1.48

1.83

1.67

3.48

1.98

.74

1.00

* The Multipliers can be interpreted as the increase or decrease in the failure rate in moving from a product that has the initial value listed to one that has the second value. Thus, all else equal, a product that is cannabilalized is 3.06 times as likely to exit as one that is not cannabalized. 
TABLE 5

Means, Standard Deviations, and Correlations for Mainframe Product Entry Analyses

\begin{tabular}{lrrrrrrrrr}
\hline Variable & $\mathbf{1}$ & $\mathbf{2}$ & $\mathbf{3}$ & $\mathbf{4}$ & $\mathbf{5}$ & $\mathbf{6}$ & $\mathbf{7}$ & $\mathbf{8}$ \\
\hline Mean & .37 & 75.91 & 0.09 & 3.03 & 17.37 & 16.56 & 11.60 & 33.98 \\
S.D. & .68 & 3.93 & 0.28 & 2.32 & 5.54 & 5.14 & 6.52 & 11.50 \\
\hline & & & & & & & & & \\
1. Product Entry & & 0.08 & -0.09 & -0.09 & 0.09 & -0.01 & 0.02 & 0.05 \\
2. Year & & & 0.03 & -0.01 & 0.33 & 0.26 & 0.30 & 0.41 \\
3. No Models in Size Class & & & & 0.55 & -0.09 & 0.01 & 0.04 & -0.02 \\
4. Time Since Last & & & & & -0.12 & 0.01 & 0.09 & -0.10 \\
Product Introduction & & & & & & & & \\
5. Density in Size Class & & & & & & -0.08 & 0.51 & -0.24 \\
6. Density of Adjacent & & & & & & & 0.26 & -0.17 \\
$\quad$ Lower Size Class & & & & & & & & \\
7. Density of Adjacent & & & & & & & & -0.58
\end{tabular}

Higher Size Clas

8. Density of Nonlocal

Non Adjacent Size Classes 
Table 6

Poisson Models of Mainframe Product Introductions: 1969-1982"

\begin{tabular}{|c|c|c|c|c|}
\hline & (1) & $(2)$ & (3) & (4) \\
\hline Constant & $\begin{array}{r}-1.41 * * \\
(.302)\end{array}$ & $\begin{array}{r}-1.23^{* *} \\
(.309)\end{array}$ & $\begin{array}{c}.354 \\
(.802)\end{array}$ & $\begin{array}{r}.882 \\
(1.45)\end{array}$ \\
\hline Entry in 1971 or 1972 & $\begin{array}{c}.521 \\
(.312)\end{array}$ & $\begin{array}{c}.546^{\star} \\
(.312)\end{array}$ & $\begin{array}{r}.576^{*} \\
(.313)\end{array}$ & $\begin{array}{c}.665^{*} \\
(.362)\end{array}$ \\
\hline Entry in 1973 or 1974 & $\begin{array}{l}-.319 \\
(.366)\end{array}$ & $\begin{array}{r}-.269 \\
(.367)\end{array}$ & $\begin{array}{c}.077 \\
(.379)\end{array}$ & $\begin{array}{c}.035 \\
(.444)\end{array}$ \\
\hline Entry in 1975 or 1976 & $\begin{array}{l}-.0868 \\
(.340)\end{array}$ & $\begin{array}{l}-.0385 \\
(.340)\end{array}$ & $\begin{array}{c}.140 \\
(.350)\end{array}$ & $\begin{array}{c}.259 \\
(.446)\end{array}$ \\
\hline Entry in 1977 or 1978 & $\begin{array}{c}.0449 \\
(.326)\end{array}$ & $\begin{array}{r}.102 \\
(.327)\end{array}$ & $\begin{array}{c}.188 \\
(.330)\end{array}$ & $\begin{array}{c}.277 \\
(.384)\end{array}$ \\
\hline Entry in 1979 or 1980 & $\begin{array}{c}.385 \\
(.307)\end{array}$ & $\begin{array}{c}.439 \\
(.308)\end{array}$ & $\begin{array}{c}.674^{\star \star} \\
(.329)\end{array}$ & $\begin{array}{c}.888 \\
(.578)\end{array}$ \\
\hline Entry in 1981 or 1982 & $\begin{array}{r}.519^{*} \\
(.302)\end{array}$ & $\begin{array}{r}.558^{*} \\
(.302)\end{array}$ & $\begin{array}{l}1.20^{\star \star} \\
(.440)\end{array}$ & $\begin{array}{l}1.53^{*} \\
(.886)\end{array}$ \\
\hline IBM & $\begin{array}{l}.446^{\star} \\
(.262)\end{array}$ & $\begin{array}{l}.477^{*} \\
(.263)\end{array}$ & $\begin{array}{l}.440^{*} \\
(.265)\end{array}$ & $\begin{array}{l}.441^{*} \\
(.264)\end{array}$ \\
\hline$N C R$ & $\begin{array}{l}.617^{* *} \\
(.326)\end{array}$ & $\begin{array}{l}.523 \\
(.330)\end{array}$ & $\begin{array}{l}.464 \\
(.331)\end{array}$ & $\begin{array}{l}.463 \\
(.331)\end{array}$ \\
\hline UNI & $\begin{array}{l}.043 \\
(.303)\end{array}$ & $\begin{array}{l}.0635 \\
(.305)\end{array}$ & $\begin{array}{l}.006 \\
(.307)\end{array}$ & $\begin{array}{l}-.007 \\
(.307)\end{array}$ \\
\hline HON & $\begin{array}{l}.529^{* *} \\
(.263)\end{array}$ & $\begin{array}{l}.565^{\star \star} \\
(.264)\end{array}$ & $\begin{array}{l}.543^{\star \star *} \\
(.265)\end{array}$ & $\begin{array}{l}.537^{ \pm *} \\
(.265)\end{array}$ \\
\hline BUR & $\begin{array}{l}.0510 \\
(.298)\end{array}$ & $\begin{array}{l}.078 \\
(.299)\end{array}$ & $\begin{array}{l}.0681 \\
(.299)\end{array}$ & $\begin{array}{l}.067 \\
(.299)\end{array}$ \\
\hline CDC & $\begin{array}{l}.589^{* *} \\
(.252)\end{array}$ & $\begin{array}{l}.620^{\star *} \\
(.253)\end{array}$ & $\begin{array}{l}.586^{* *} \\
(.255)\end{array}$ & $\begin{array}{l}.587^{\star *} \\
(.255)\end{array}$ \\
\hline GEL & $\begin{array}{l}-.553 \\
(.448)\end{array}$ & $\begin{array}{l}-.537 \\
(.450)\end{array}$ & $\begin{array}{l}-.458 \\
(.457)\end{array}$ & $\begin{array}{l}-.465 \\
(.456)\end{array}$ \\
\hline RCA & $\begin{array}{l}-.503^{*} \\
(.537)\end{array}$ & $\begin{array}{l}-450 \\
(.538)\end{array}$ & $\begin{array}{l}-.342 \\
(.542)\end{array}$ & $\begin{array}{l}-.360 \\
(.543)\end{array}$ \\
\hline
\end{tabular}

- Standard errors are in parentheses. Size Class 3 is omitted since density measures for size class 2 are not available. Adjacent high density for size class 7 is set to zero.

** $p<.05$. * $p<.10$. 
Table 6 Continued

Poisson Models of Mainframe Product Introductions: 1969-1982

(1)

(2)

(3)

(4)

Size Class 5

$-.356^{*} \quad-.905^{* *} \quad-.901$

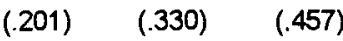

Size Class 6

$-.602^{* *} \quad-1.28^{* *} \quad-1.30^{* *}$

$\begin{array}{lll}(.229) & (.409) \quad(.440)\end{array}$

Size Class 7

$\begin{array}{rll}-.151 & -.853^{\star \star} & -1.20\end{array}$

$\begin{array}{lll}(.212) & (.392) \quad(.816)\end{array}$

No Models in Size Class

Time since last Product Introduction

$-.501 \quad-.486$

(.441) $\quad(.443)$

$-.017 \quad-.0172$

(.044) (.0448)

Density in Size Class

$-.073^{* *} \quad-.0746^{*}$

(.0353) (.0369)

Density of Adjacent Lower Size Class

$-.007$

$(.0334)$

Density of Adjacent Higher Size Class

$-.0267$

$(.0406)$

Density of Nonlocal-Nonadjacent

Size Classes

$-.004$

(.0256)

- Log Likelihood

357.7

375.3

353.5

350.3

350.1

- Log Likelihood (without covariates)

Degrees of Freedom

Number of Firm-Year Spells

375.3

$\begin{array}{llll}14 & 17 & 20 & 23\end{array}$

$\begin{array}{llll}465 & 465 & 465 & 465\end{array}$

Number of Events

172

172

172

172

- Standard errors are in parentheses. Size Class 3 is omitted since density measures for size class 2 are not available. Adjacent high density for size class 7 is set to zero.

$* * 0.05 . * p<.10$. 


\section{Table 7}

\section{Effects of Changes in the Independent Variables on the Multiplier of the Rate of Product Entry}

Independent Variables

1. Time

2. Size Class

3. Density in Size Class

4. Firm Effects
Change in Independent Variables
Multiplier of the Rate Of Product Exit
Change from: $1969-1970$ to $1977-1978$

Change from: $1969-1970$ to $1979-1980$

Change from: $1969-1970$ to $1981-1982$

Change from Size Class 5 to Size Class 4 Change from Size Class 6 to Size Class 4 Change from Size Class 7 to Size Class 4

Change from: 32 to 6

19 to 6

13 to 6

Change from: NCR to IBM Univac to IBM

Honeywell to IBM

Burroughs to IBM

Control Data to IBM

GEL to IBM

RCA to IBM
1.21

1.96

3.32

2.47

3.60

2.35

6.72

2.55

1.66

.98

1.56

.91

1.45

.86

2.47

2.22 